\title{
IURI M. LOTMAN Y LA ESCUELA SEMIÓTICA DE TARTU-MOSCÚ: BIBLIOGRAFÍA EN ESPAÑOL, FRANCÉS, INGLÉS, ITALIANO, PORTUGUÉS Y ALEMÁN
}

\author{
Manuel Cáceres Sánchez
}

\author{
Universidad de Granada
}

\section{Nota previa.}

La bibliografía que aquí se ofrece pretende actualizar la selección bibliográfica de (y sobre) Iuri Lotman y la Escuela Semiótica de Tartu-Moscú que, en 1993, presenté en la revista Discurso.

En ese mismo año, apareció en Tallinn el tercer volumen de la Antología de artículos de Iuri Lotman, al final del cual figura una Lista de trabajos de I.M. Lotman, preparada por L. Kiselev. Este repertorio bibliográfico, que abarca lo publicado por Iuri Lotman entre 1949 y 1992, contiene 813 entradas. La mitad de éstas corresponden a publicaciones en lengua rusa, mientras que casi todas las restantes son traducciones de sus trabajos a otras lenguas: estonio, alemán, francés, español, portugués, italiano, inglés, rumano, sueco, húngaro, polaco, finés, lituano, japonés, serbocroata, checo, eslovaco, etc.

Aunque esa recopilación no recoge exhaustivamente libros y artículos publicados en lenguas distintas a la rusa, es interesante comprobar, por ejemplo, que, desde 1950, se publican artículos de Lotman en estonio (muchos de 
ellos en periódicos y revistas culturales); que las traducciones inglesas (desde 1973) son posteriores a las primeras que se dan a conocer en italiano (1967), francés (1964), rumano (1967), checo (1968) o alemán (1959); o que los trabajos de Lotman tienen especial eco en países eslavos como Polonia o las antiguas Checoslovaquia y Yugoslavia.

En las páginas siguientes se recogen unos 700 títulos, casi 200 más que los citados en Discurso. Como entonces, nuestra bibliografía tiene en cuenta exclusivamente lo publicado en español, inglés, francés, italiano, portugués y alemán. Cuando existe traducción al español, se cita en primer lugar, y a continuación, por orden cronológico, las publicaciones en las demás lenguas. Además, se indica, cuando ha sido posible, el lugar y el año de publicación del trabajo original (B, Budapest; D, Debrecen; L, Leningrado; M, Moscú; R, Riga; S, Saransk; T, Tartu; Tal, Tallinn; V, Varsovia).

Mantengo también la división en cinco partes, aunque he introducido en la estructura de la bibliografía de Iuri Lotman la distinción entre sus libros (los que aparecieron en ruso como tales) y los compendios de artículos editados, por ejemplo, en Italia o en Alemania. Cuando en los compendios o libros monográficos figuran, además de Lotman, otros autores o editores (Uspenski, Escuela de Tartu...) se citan en el apartado 2.1. (MONOGRAFIAS. Libros):

1. BIBLIOGRAFÍAS.

2. MONOGRAFÍAS.

\subsection{Libros.}

2.2. Revistas.

3. BIBLIOGRAFÍA DE IURI M. LOTMAN

3.1. Libros.

3.2. Compendios de artículos.

3.3. Artículos.

3.4. Trabajos en colaboración.

3.5. Entrevistas.

4. BIBLIOGRAFÍA DE LA ESCUELA SEMIÓTICA DE TARTUMOSCÚ.

5. BIBLIOGRAFÍA SOBRE LOTMAN Y LA ESCUELA SEMIÓTICA DE TARTU-MOSCÚ.

Agradezco a Desiderio Navarro y a Jüri Talvet las informaciones que, desde Cuba y Estonia, me han hecho llegar y que han enriquecido este trabajo bibliográfico.

\section{BIBLIOGRAFÍAS}

AA. VV. (1982). Finitis Duodecim Lustris. 60 - . , Tallinn, , 176 páginas.

AA. VV. (1991). Papers of Tartu University on Russian Literature and Semiotics (1958-1990). Bibliographical Index. Tartu: Tartu University/Dept. of Russian Literature.

CÁCERES SÁNCHEZ, M. (1993). «Selección bibliográfica». Discurso. Revista Internacional de Semiótica y Teoria Literaria 8, 139-184. 
EIMERMACHER, K. (1974). Arbeiten Sowjetischer der Moskauer und Tartuer Schule (Auswahlbibliographie). Kronberg: Scriptor, 180 páginas (Skripten Literaturwissenschaft, 14).

Eimermacher, K. y ShishKoff, S. (1977). Subject Bibliography of Soviet Semiotics. The Moscow-Tartu School. Ann Arbor: University of Michigan, 153 páginas.

FERRARI-BRAvo, D. (1978). «La scienza letteraria sovietica in Italia. Saggio bibliografici 1960-1977». Strumenti Critici 36-37 (Torino, Ottobre), 353-417.

KISELEV, L. (1993). « . . [Lista de trabajos de I. M. Lotman]». En Iuri M. Lotman, [Artículos escogidos en tres tomos]. Tallinn: Aleksandra Publishers, tomo III, 441-482.

Shukman, A. (1978). «The Moscow-Tartu Semiotics School: A Bibliography of Works and Comments in English». PTL. A Journal for Descriptive Poetics and Theory of Literature 3, 593-601.

\section{MONOGRAFÍAS}

\subsection{Libros}

BARAN, H., ed. (1974). Semiotics and Structuralism. Readings from the Soviet Union. White Plains, N.Y.: International Arts and Sciences, 367 páginas.

Broms, H. y KaUfmann, R., eds. (1988). Semiotics of Culture. Proceedings of the 25th Symposium of the Tartu-Moscow School of Semiotics, Imatra, Finland, 27th-29th July, 1987. Helsinki: Arator, 272 páginas.

Comunicación, ed. (1972). Los sistemas de signos. Teoría y práctica del estructuralismo soviético. Madrid: Alberto Corazón (Trad. de Gloria Kue).

ECO, U. y FACCANI, R., eds. (1969). Semiotica della letteratura in URSS. Milano: Bompiani.

EIMERMACHER, K., ed. (1986). Semiotica Sovietica. Sowjetische Arbeiten der Moskauer und Tartuer Schule zu Sekundären Modellbildenden Zeichensystemen (1962-1973). Aachen: Rader.

- (1987). Cultural Semiotics in the Soviet Union. Bochum: Studienverlag.

EIMERMACHER, K. y GRZYBEK, P., eds. (1991). Zeichen-Text-Kultur. Studien $z u$ den sprach und kultursemiotischen Arbeiten von Vjac.Vs Ivanov und $V$. N. Toporov. Bochum: Brockmeyer.

EIMERMACHER, K., GrzYbeK, P. y WitTe, G., eds. (1989). Issues in Slavic Literary and Cultural Theory. Studien zur Literatur und Kulturtheorie in Osteuropa. Bochum: Universitätsverlag Dr. Norbert Brockmeyer.

ENG, J. V. DER y GRYGAR, M., eds. (1973). Structure of Texts and Semiotics of Culture. The Hague/Paris: Mouton.

FACCANI, R. y ECO, U., eds. (1969). I sistemi di segni e lo strutturalismo sovietico. Milano: Bompiani.

FAwCETT, R. P. et alii, eds. (1984). The Semiotics of Culture and Language. Vol. 2: Language and other Semiotic Systems of Culture. London/Dover: Pinter.

FLEISCHER, M. y GRZYBEK, P., eds. (1989-1991). Znakolog. An International Yearbook of Slavic Semiotics. Bochum: IFISS, Vols. 1 (1989), 2 (1990), 3 (1991).

Halle, M. et alii, eds. (1984). Semiosis: Semiotics of the History of Culture. Ann Arbor: Michigan Slavic Contributions N. 10. 
KIEFER, F., ed. (1973). Trends in Soviet Theoretical Linguistics. Dordrecht/ Boston: Reidel, 438 páginas.

KrIsteVA, J. et alii, eds. (1971). Essays in Semiotics. Essais de sémiotique. The Hague/Paris: Mouton.

Lotman, J. y Escuela de TARTU (1979). Semiótica de la Cultura. Madrid: Cátedra, 245 páginas (Introd., Selecc. y notas de J. Lozano; trad. de Nieves Méndez).

LOTMAN, Y. M. y OUSPENSKI, B. A., eds. (1976). Travaux sur les systèmes de signes. École de Tartu. Textes choisis et présentés par J.M. Lotman et B.A. Ouspenski, traduits du russe par Anne Zouboff. Bruxelles: Complexe, 249 páginas.

LotMAN, J. M. y USPENSKIJ, B. A., eds. (1973). Ricerche semiotiche (Nuove tendenze delle scienze umane nell'URSS). Torino: Einaudi, 470 páginas.

LOTMAN, J. M. y USPENSKIJ, B. A. (1975). Tipologia della cultura (a cura di Remo Faccani e Marzio Marzaduri. Prefazione di Remo Marzaduri). Milano: Bompiani, (1987); edizione ridevuta e corretta, Milano: Bompiani («Saggi Tascabili»), 1995, 299 páginas.

LotMAn, J. M. y USPENSKIJ, B. A. (1975a). Semiotica e cultura. Milano/Napoli: R. Ricciardi, LXXX-138 páginas (Trad. e Introd. D. Ferrari Bravo).

LUCID, D. P., ed. (1977). Soviet Semiotics. Baltimore/London: The Johns Hopkins University Press, 1988, 259 páginas.

Maranda, P., ed. (1974). Soviet Structural Folkloristics. The Hague/Paris: Mouton, Vol. I.

NAKhImovski, A. D. y Stone NAKhimovski, A., eds. (1985). The Semiotics of Russian Cultural History: Essays. Ithaca/London: Cornell University Press, 299 páginas.

O'Toole, L. M. y Shukman, A., eds. (1975,1976). Poetika. Russian Poetics in Translation. Colchester: University of Essex, 3 vols. [vol. 1 (1975), 77 págs.; vol. 2 (1976), 84 págs.; vol. 3 (1976), 81 págs.].

Prevignano, C., ed. (1979). La semiotica nei paesi slavi. Programmi, problemi, analisi. Milano: Feltrinelli.

Schnaiderman, B., ed. (1979). Semiótica Russa. São Paulo: Perspectiva, 307 páginas.

ShUKMAN, A., ed. (1984). The Semiotics of Russian Culture. Ann Arbor: University of Michigan/Dep. of Slavic Languages and Literature, 341 páginas.

\subsection{Revistas}

- (1968). Tel Quel (La sémiologie aujourd'hui en URSS) 35.

- (1973). Change (Transformer/Traduire) 14.

- (1974). Soviet Studies in Literature: A Journal of Translation 10, 4.

- (1976). Dispositio (Soviet Semiotics of Culture) 3, 1.

- (1976). Soviet Studies in Literature 12, 2.

- (1977). Russian Literature 5, 1.

- (1978). New Literary History (Soviet Semiotics and Criticism: An Antho$\log y) 9,2$.

- (1980). Strumenti Critici 42-43.

- (1993). Discurso. Revista Internacional de Semiótica y Teoría Literaria (Iuri M. Lotman y la Escuela Semiótica de Tartu-Moscú, treinta años después) 8.

- (1993). Escritos. Revista del Centro de Ciencias del Lenguaje (La Escuela de Tartu. Homenaje a Iuri M. Lotman) 9. 


\section{BIBLIOGRAFÍA DE IURI M. LOTMAN}

\subsection{Libros}

- (T, 1964). Vorlesungen zu einer strukturalen Poetik: Einführung, Theorie des Verses. München: Fink, 1972, 233 páginas (Ed. K. Eimermacher y W. Jachnow).

- (M, 1970). Estructura del texto artístico. Madrid: Istmo, 1978 (1982²), 364 páginas (Trad. Victoriano Imbert). Die Struktur Literarischer Texte, München: Fink, 1972, 430 páginas (Ed. R.-D. Keil). Die Struktur des Künstlerischen Textes, Frankfurt: Shurkamp, 1973, 470 páginas. La struttura del testo, Milano: Mursia, 1972 (1985²), 361 páginas (Ed. E. Bazzarelli). La structure du texte artistique, París: Gallimard, 1973, 415 páginas (Pref. H. Meschonnic). The Structure of the Artistic Text, Ann Arbor: Michigan Slavic Cont., 1977, 300 páginas. A Estrutura do Texto Artistico, Lisboa, 1978, 479 páginas.

- (L, 1972). Die Analyse des poetischen Textes. Kronberg: Scriptor, 1975, 203 páginas (Trad. R. Grübel). Analysis of the Poetic Text. Ann Arbor (Mich.): Ardis, 1976, 309 páginas (Ed. y trad. Johnson D. Barton; Bibliogr. L. Fleishman).

- (Tal, 1973). Estética y semiótica del cine. Barcelona: Gustavo Gili, 1979, 153 páginas (Versión castellana del original ruso de José Fernández Sánchez y revisión general de Joaquim Romaguera i Ramió). Semiotics of Cinema, Ann Arbor (Mich.): Ardis, 1976, 106 páginas. Probleme der Kinoästhetik. Einführung in die Semiotik der Films, Frankfurt: Syndikat Autoren und Verlagsgesellschaft, 1977, 162 páginas. Sémiotique et esthétique du cinéma, Paris: Seuil, 1977, 188 páginas. Estética e Semiótica do cinema, Lisboa, 1978, 182 páginas. Introduzione alla semiotica del cinema, Roma: Officina, 1979, 141 páginas; Edizioni del Prisma, 1994, 175 páginas (trad. G. Beltrame).

- (T, 1975). Il testo e la storia: L' "Evgenij Onegin» di Puškin. Bologna: Il Mulino, 1985, 179 páginas (Trad. M. Boffito; ed. C. Strada Ianovič; introd. V. Strada).

- (L, 1981). Alexander Puschkin. Leipzig: Reclam, 1989, 419 páginas. Puškin. Vita di Aleksandr Sergeevič Puškin, Padova: Liviana, 1990, XX-226 páginas (trad. F. Fici Giusti).

- (M, 1993). La cultura e l'esplosione. Prevedibilità e imprevedibilità. Milano: Feltrinelli, 1993, 224 páginas (trad. Caterina Valentino).

- (1994). Cercare la strada. Modelli della cultura. Venezia: Marsilio, 1994, 108 páginas (trad. N. Marcialis; introd. M. Corti).

\subsection{Compendios de artículos}

- (1974). Aufsätse zur Theorie und Methodologie der Literatur and Kultur. Kronberg: Scriptor, 1974, 452 páginas.

- (1980). Testo e contesto. Semiotica dell'arte e della cultura. Roma/Bari: Laterza (Biblioteca de Cultura Moderna, 834), 1980, 234 páginas (ed. S. Salvestroni).

- (1981). Kunst als Sprache: Untersuchungen zum Zeichencharakter von Literatur und Kunst. Leipzig: Reclam, 1981, 501 páginas. 
- (1984). Da Rousseau a Tolstoj. Saggi sulla cultura russa. Bologna: Il Mulino, 1984, 346 páginas (Ed. C. Strada, trad. M. Boffito).

- (1985). La semiosfera. L'asimmetria e il dialogo nelle strutture pensanti. Venezia: Marsilio, $1985\left(1992^{2}\right), 311$ páginas (Trad. e introd. S. Salvestroni).

- (1990a). Universe of the Mind. A Semiotic Theory of Culture. New York/London: I.B. Tauris, 1990, 288 páginas (Transl. by Ann Shukman; introd. by Umberto Eco).

- (1990b). Sémiotique de la culture Russe. Études sur l'histoire. Lausanne, 1990, 516 páginas.

\subsection{Artículos}

- (1959). «Neue Materialen über die Anfänge der Beschäftigung mit Schiller in der russischen Literatur». Wissenschafliche Zeitschrift der E. Moritz Arnd-Universität Greifswald. Gessellschafts und Sprachwissenschaftliche Reihe 8, 516 (1958-1959), 419-434.

- (T, 1962). «Le origini della corrente tolstoiana nella letteratura russa degli anni 1830-40». En Tolstoj oggi, 313-394. Firenze, 1980.

- (1963). «Die Entwicklung des Romans in der russischen Literatur des 18. Jahrhunderts». Studien zur Geschichte der russischen Literatur des 18. Jahrhunderts. Veröffentlichungen des Instituts für Slawistik I, 28 (Berlin, 1963), 22-51.

- (T, 1963). «Sobre la delimitación lingüística y literaria de la noción de estructura». En R. Barthes y otros, Estructuralismo y literatura. Buenos Aires: Nueva Visión, 1970, 107-123. «Sur la délimitation linguistique et littéraire de la notion de structure», Linguistics 6 (The Hague, 1964), 59-72. «Zur Distinktion des linguistischen und des literaturwissenschaftlichen Strukturbergriffs», en Formalismus, Strukturalismus Geschichte, Kronberg: Scriptor, 1974, 105-120; y en Textsemiotik als Ideologiekritik, Frankfurt, 1977, 131-148.

— (T, 1964a). «Le hors-texte». Change 6 (Paris, 1970), 68-81 [De su libro $\mathrm{T}, 1964]$.

- (T, 1964b). «Le problème de la traduction poétique». Change 14 (Paris, 1973), 14-18 [De su libro T, 1964].

- (T, 1964c). «Texte et hors-texte». Change 14 (Paris, 1973), 32-44 [De su libro T, 1964].

- (T, 1964d). «Zwei Kapitel zur strukturellen Poetik». Sprache im technischen Zeitalter 38 (Apr.-Jun. 1971), 110-120 [De su libro T, 1964].

- (T, 1964e). «Introducción a las lecciones de poética estructural». La Gaceta de Cuba. Criterios [Primera época] 105 (La Habana, Agosto-Septiembre 1972), 30-32; y con el título «Lecciones de poética estructural (Introducción)», en Textos y contextos: Una ojeada en la teoría literaria mundial (Selección, traducción y prólogo de Desiderio Navarro), Vol. I, La Habana: Arte y Literatura, 1986, 141-156 [De su libro T, 1964].

- (T, 1964f). «Discorso d'apertura». En Prevignano, ed. (1979), 188-190.

- (1965). «Lomonosovs Stellung in der Geschichte des russischen gesellschaftlichen Denkens». Zeitschrift für Slawistik X, 5 (Berlin, 1965), 682-701.

- (T, 1965a). «The Problem of Meaning in Secondary Modeling Systems». New Literary History (1977), 22-37. 
- (T, 1965b). «Il concetto di spazio geografico nei testi medievali russi». En Lotman y Uspenskij (1975), 183-192.

- (T, 1966a). "Valor modelizante de los conceptos de "fin" y "principio"». En Lotman y Escuela de Tartu (1979), 199-203. «Funzione modellizzante dei concetti di "fine" e "inizio"», Il verri 2 (1973), 25-31; con el título "Valore modellizzante dei concetti di "fine" e "inizio"", en Lotman y Uspenskij (1975), 135-141. «On the Modeling Significance on the Concepts "Beginning" and "End" in Artistic Texts", Russian Poetics in Translation, Vol. 3, General Semiotics (Colchester, University of Essex, 1976), 7-11. «La signification modélisante des concepts de "fin" et de "début" dans les textes artistiques», en Lotman y Ouspenski, eds. (1976), 197-201. «Die modellbindende Bedeutung der Begriffe "Anfang" und "Ende" in künstlerischen Texten», en Eimermacher, ed. (1986), 829-834.

- (T, 1966b). «The Structure of Eugene Onegin». En Russian Views of Pushkin's Eugene Onegin. Bloomington, 1988, 91-114.

- (T, 1966c). «Problems in the Tipology of Texts». En Lucid, ed. (1977), 119-124.

- (1967). «Metodi esatti nella scienza letteraria sovietica». Strumenti Critici 1, 2 (Torino, 1967), 107-127.

- (M, 1967). «Los estudios literarios deben ser una ciencia». En Textos y contextos: Una ojeada en la teoría literaria mundial (Selección, traducción y prólogo de Desiderio Navarro), Vol. I, La Habana: Arte y Literatura, 1986, 73-86.

- (T, 1967a). «Tesi sull'Arte come sistema secondario di modellizzazione». En Lotman y Uspenskij (1975a), 1-27.

- (T, 1967b). «El problema de una tipología de la cultura». Casa de las Américas 71 (La Habana, 1972), 43-48; en Comunicación, ed. (1972), 85-98; y en Semiótica y praxis, Barcelona: Redondo, 1973. «Problèmes de la typologie des cultures», Social Science. Information sur les sciences sociales VI, 2/3 (Apr.-Jun. 1967), 29-38; y en Kristeva y otros, eds. (1971), 46-56. «Il problema di una tipologia della cultura», en Faccani y Eco, eds. (1969), 309-318. «Problems in the Tipology of Culture», en Lucid, ed. (1977), 213221. «Sobre o problema da tipologia da cultura», en B. Schnaiderman, ed. (1979), 31-41.

- (T, 1967c). «L'opposizione 'onore-gloria' nei testi profani del periodo di Kiev del Medioevo russo». En Lotman y Uspenskij (1975), 251-269.

- (1968). «Die Frühanfklärung und die Entwicklung des gesellschaftlichen Denkens in Russland». Studien zur Geschichte der Russischen Literatur des 18. Jahrhunderts. Veröffentlichungen des Instituts für Slawistik III (Berlin, 1968), 93-119, 557-559.

- (T, 1968a). «Sémantique du nombre et type de culture». Tel Quel 35 (1968), 24-27. «Numerical Semantics and Cultural Types», en Lucid, ed. (1977), 227-231.

- (T, 1968b). «Zwei Gedicht-Analysen». En Eimermacher, ed. (1986), 429-455.

- (T, 1968c). «Numerical Semantics and Cultural Types». En Lucid, ed. (1977), 227-231.

- (T, 1968d). «Il problema dello spazio artistico in Gogol'». En Lotman y Uspenskij (1975), 193-248. «Artistic Space in Gogol's Prose», Russian Literature 24 (1990), 199-241.

- (V, 1968; T, 1969a). «On the Metalanguage of a Typological Description of Culture». Semiotica 14, 2 (1975), 97-123. «Il metalinguaggio delle descrizioni tipologiche della cultura», en Lotman y Uspenskij (1975), 145-181. 
- (T, 1969b). «Einige prinzipielle Schwierigkeiten bei der strukturellen Textbeschreibung». Sprache im Technischen Zeitalter 48 (Oct.-Dec. 1973), 278284. «On Some Principle Difficulties in the Structural Description of a Text», Linguistics 121 (1974), 57-64.

- (T, 1969c). «Language and Reality in the Early Pasternak». En V. Erlich (ed.), Pasternak: A Collection of Critical Essays, Englewood Cliffs:Prenlice-Hall, 21-38.

- (T, 1969d). «Sobre algumas dificuldades de princípio na descrição estrutural de um texto». En B. Schnaiderman, ed. (1979), 131-138.

- (M, 1970a). «Il concetto di testo». En Teoria della letteratura. Bologna, 1975, 86-87 [De su libro M, 1970].

- (M, 1970b). «La ripetibilità al livello fonologico». En Teoria della letteratura. Bologna, 1975, 236-241 [De su libro M, 1970].

- (M, 1970c). «La struttura del testo poetico». En Teoria della letteratura. Bologna, 1975, 133-139 [De su libro M, 1970].

- (M, 1970d). «Point of View in a Text». New Literary History VI, 2 (1975), 339-352 [De su libro M, 1970].

- (T, 1970a). «El problema del signo y del sistema sígnico en la tipología de la cultura anterior al siglo XX». En Lotman y Escuela de Tartu (1979), 41-66. «Il problema del segno e del sistema segnico nella tipologia della cultura russa prima del XX secolo», en Lotman y Uspenskij, eds. (1973), 40-63.

- (T, 1970b). «Culture and Information». Dispositio. Revista Hispánica de Semiótica Literaria 1, 3 (University of Michigan, 1976), 213-219.

- (T, 1970c). «Proposte per il programma della 'IV Scuola estiva sui sistemi modellizzanti secondari'». En Prevignano, ed. (1979), 191-193. «Vorschläge zum Programm der IV. Sommer-Schule über sekundäre modellbildende Systeme», en Eimermacher, ed. (1986), 81-84.

- (T, 1970d). «Semiótica de los conceptos de "vergüenza" y "miedo"». En Lotman y Escuela de Tartu (1979), 205-208. «Semiotica dei concetti di "vergogna" e "paura"», en Lotman y Uspenskij (1975), 271-275. «La sémiotique des concepts de "peur" et de "honte" dans le mécanisme de la culture», en Lotman y Ouspenski, eds. (1976), 54-57. «Zur Semiotik der Begriffe "Scham" und "Angst" im Mechanismus der Kultur», en Eimermacher, ed. (1986), 835-838.

- (T, 1970e). «Introduzione», a Lotman y Uspenskij (1975), 25-35.

- (T, 1971a). «Notes on the Structure of a Literary Text». Semiotica 14, 2 (1975), 199-205.

- (T, 1971b). «La cultura e il suo "insegnamento" come caratteristica tipologica». En Lotman y Uspenskij (1975), 69-81. «Das Problem der "Kulturvermittlung" als ihr typologisches Charakteristikum von Kultur», en Eimermacher, ed. (1986), 839-851.

- (L, 1972a). «Analysis of a Poetic Text: The Structure of Poetry». Soviet Studies in Literature: A Journal of Translations 10, 2 (1974), 3-41 [De su libro L, 1972].

- (L, 1972b). «Sulla poesia: testo e sistema». Problemi: Periodico quadrimestrale di cultura 52 (1978), 132-146 [De su libro L, 1972].

- (L, 1972c). «Das Problem des poetischen Sujets». En Eimermacher, ed. (1986), 479-483 [De su libro L, 1972].

- (S, 1973). «Sobre el contenido y la estructura del concepto de "literatura artística". Criterios 31 (La Habana, 1994), 237-257. «The Content and 
Structure of the Concept of "Literature"», PTL. A Journal for Descriptive Poetics and Theory of Literature 1 (1976), 339-356.

- (T, 1973a). «Observations on the Structure of the Narrative Text». Soviet Studies in Literature: A Journal of Translations 10, 4 (1974), 75-81; en The Soviet Review 14, 2 (1975), 59-65; y con el título «The Structure of the Narrative Text», en Lucid, ed. (1977), 193-197.

- (T, 1973b). «On the Mythological Code of Plotted Texts». Soviet Studies in Literature: A Journal of Translations 10, 4 (1974), 82-87.

- (T, 1973c). «The Individual Creative Career and the Tipology of Culture Codes». Soviet Studies in Literature: A Journal of Translations 10, 4 (1974), 88-90.

- (T, 1973d). «El arte canónico como paradoja informacional». Criterios 30 (1991), 23-29.

- (T, 1973e). «The Discrete Text and Iconic Text. Some Remarks on the Structure of Narrative». New Literary History VI, 2 (1975), 333-338.

- (T, 1973f). «Theater and Theatricality in the Order of Early Nineteenth Century Culture». Soviet Studies in Literature: A Journal of Translations XI, 2/3 (1975), 155-185; The Soviet Review 16, 4 (1975/1976), 53-83; en Baran, ed. (1974), 33-63; y en Shukman, ed. (1984), 141-164. «Il teatro e la teatralità nel sistema della cultura all'inizio del secolo XIX», en Da Rousseau a Tolstoj, 1984.

- (T, 1973g). «O. M. Freidenberg as a Student of Culture». En Baran, ed. (1974), 257-268; y en Soviet Studies in Literature: A Journal of Translations 12, 2 (1976), 3-11.

- (T, 1973h). «The Structure of Ideas in Pushkin's Poem "Andzhelo"», Russian Poetics in Translation, Vol. 2, Poetry and Prose (Colchester: University of Essex, 1976), 66-84.

- (T, 1973i). «The Origin of Plot in the Light of Typology». Poetics Today 1, $1 / 2$ (1979), 161-184.

- $(\mathrm{T}, 1973 \mathrm{j})$. «I due modelli della comunicazione nel sistema della cultura». En Lotman y Uspenskij (1975), 111-133. «Two Models of Communication», en Lucid, ed. (1977), 99-102. «Sur deux modèles de communication dans le système de la culture», Linguistique et poétique, Moscú, 1982, 205224. «Zwei Kommunikationsmodelle im System der Kultur», en Eimermacher, ed. (1986), 909-930.

- (Tal, 1973). «L'illusione della realtà». Rassegna sovietica 6 (1973), 107-119 [De su libro Tal, 1973].

- (M, 1974). «Un modelo dinámico del sistema semiótico». En Lotman y Escuela de Tartu (1979), 93-110. «Un modèle dynamique du système sémiotique», en Lotman y Ouspenski, eds. (1976), 77-93. «The Dynamic Model of a Semiotic System», Semiotica, 21, 3/4 (1977), 193-210.

- (T, 1974a). «Du rapport primaire/secondaire dans les systèmes modelants de communication». Sémiotique. Recherches internationales à la lumière du marxisme (Paris) 81, 4 (1974), 38-42. «Primary and Secondary Communication-Modeling Systems», en Lucid, ed. (1977), 95-101.

- (T, 1974b). «L'interrelation de la langue naturelle et du mètre dans le mécanisme du vers». En Lotman y Ouspenski, eds. (1976), 213-217.

- (T, 1974c). «Gogol and the Correlation of "The Culture of Humor" with the Comic and Serious in the Russian National Tradition». En Baran, ed. (1974), 297-300; y en Soviet Studies in Literature: A Journal of Translations, 12, 2 (1976), 40-43. 
- (T, 1974d). «On the Reduction and Unfolding of Sign Systems (The Problem of "Freudianism and Semiotic Culturology")». En Baran, ed. (1974), 301-309; y en Soviet Studies in Literature: A Journal of Translations, 12, 2 (1976), 44-52. «La réduction et le déploiement des systèmes sémiotiques (Introduction au problème: le freudisme et la culturologie sémiotique)», en Lotman y Ouspenski, eds. (1976), 44-51.

- (L, 1975). «The Decembrist in Everyday Life». En Shukman, ed. (1984), 71-123; y con el título «The Decembrist in Daily Life (Everyday Behavior as a Historical-Psychological Category)», en Nakhimovski, A. D. y Stone, A., eds. (1985), 95-149.

- (T, 1975a). «Concerning Khlestakov». En Nakhimovski, A. D. y Stone, A., eds. (1985), 150-187.

- (T, 1975b). «Themes and Plot. The Theme of Cards an the Card Game in Russian Literature in the Nineteenth Century». PTL. A Journal for Descriptive Poetics and Theory of Literature 3 (1978), 455-492. «Das Thema der Karten und des Kartenspiels in der Russischen Literatur zu Beginn des 19. Jarhunderts», Kodikas/Code. An International Journal of Semiotics 2, 1 (1980), 39-63.

- (T, 1975c). «La scena e la pittura come dispositivi codificatori del comportamento culturale nella Russia del primo Ottocento». En Lotman y Uspenskij (1975), 277-291.

- (M, 1976). «Die künstlerische Natur in den russischen Volksbilderbögen». En Lubok: Der russische Volksbilderbögen. München: Katalog des Münchner Stadtmuseumus, 1985, 21-34.

- (T, 1976). «Que donne l'approche sémiotique?». Sciences Sociales 1 (1978), 223-226. «Che cosa dà l'approccio semiotico?», en Prevignano, ed. (1979), 225-228.

- (M, 1977). «La cultura come intelletto collettivo e i problemi dell'intelligenza artificiale». Centro Internazionale di Semiotica e di Linguistica: Università di Urbino, A, 66, 1977, 16 páginas; en Lotman, Testo e contesto, 1980; y con el título La cultura come mente collettiva e i problemi dell'intelligenza artificiale, Quattroventi. «Culture as Collective Intellect and the Problems of Artificial Intelligence», Russian Poetics in Translation, Vol. 6, Dramatic Structure: Poetic and Cognitive Semantics (Colchester, University of Essex, 1979), 84-96.

- (T, 1977a). «El lugar del arte cinematográfico en el mecanismo de la cultura». Criterios 30 (1991), 51-64.

- (T, 1977b). «El texto y la estructura del auditorio». Criterios 31 (La Habana, 1994), 229-236. «The Text and the Structure of its audience», New Literary History. A Journal of Theory and Interpretation 14, 1 (1982-1983), 81-87.

- (T, 1977c). «La poetica del comportamento quotidiano nella cultura russa del XVIII secolo». En Lotman, Testo e contesto, 1980. "The Poetics of Everyday Behavior in Russian», en Shukman, ed. (1984), 231-256; y con el título «The Poetics of Everyday Behaviour in Eighteenth-Century Russian Culture», en Nakhimosvki, A. D. y Stone, A., eds. (1985), 67-94.

- (T, 1978a). «La lingua orale nella prospettiva storico-culturale». Quaderni urbinati di cultura classica 6, 35 (1980), 7-16.

- (T, 1978b). «On the Language of Animated Cartoons». Russian Poetics in Translation, Vol. 8, Film Theory and General Semiotics (Colchester: University of Essex, 1981), 36-39.

- (T, 1978c). «Il fenomeno della cultura». En Lotman, Testo e contesto, 1980. 
- (1979). «The Future for Structural Poetics». Poetics 8, 6 (1979), 501-507.

- (M, 1979). «Linguaggio teatrale e pittura». Alfabeta 32 (Milano, 1982), 15-16.

- (T, 1979). «Gogol's "Tale of Captain Kopejkin": Reconstruction of the Plan and Ideo-Compositional Function». En Shukman, ed. (1984), 213-230. «La storia del capitano Kopejkin. La ricostruzione del progetto e la sua funzione ideologico-compositiva», en Lotman, La semiosfera, 1985, 267-289.

- (1980; T, 1981). «La retórica». Escritos. Revista del Centro de Ciencias del Lenguaje 9 (Puebla, México, 1993), 21-46. «Retorica», Enciclopedia, Torino: Einaudi, 1980, Vol. XI, 1047-1066.

- (T, 1980). «Semiótica de la escena». Criterios 22/24 (La Habana, 19871988), 53-77. «Semiotica della scena», Strumenti Critici. Rivista quadrimestrale di cultura e critica letteraria XV, I (Torino, Febbraio 1981), 1-29; y en Rassegna sovietica 33, 2 (1982), 3-24.

- (M, 1981). «Cerebro-Texto-Cultura-Inteligencia artificial». Criterios 31 (La Habana, 1994), 207-221. «Il cervello, il testo, la cultura, l'intelletto artificiale», Intersezioni 1 (1982), 5-16.

- (T, 1981a). «El texto en el texto». Criterios 5/12 (La Habana, 1984), 99-116; en Semiosis 24 (Xalapa, Enero-Junio de 1990); y en Criterios, edición especial (1993), 117-132. «Il testo nel testo», en Lotman, La semiosfera, 1985, 247-265.

- (T, 1981b). «La semiótica de la cultura y el concepto de texto». Escritos. Revista del Centro de Ciencias del Lenguaje 9 (Puebla, México, 1993), 15-20.

- (1982a). «Die grafische Folge: Erzählung und Gegenerzählung». Figura 3 Zyklen: Internationale Buchkunst-Ausstellung, Leipzig, 1982, 11-22.

- (1982b; M, 1983). «Kultur und Text als Sinngeneratoren». Zeitschrift für Semiotik 4, 1/2 (1982), 123-133.

- (L, 1982). «Un saggio di ricostruzione dell'intreccio di Puskin su Gesù». En Lotman, La semiosfera, 1985, 291-306.

- $(\mathrm{T}, 1982)$. «Sulla preistoria delle idee semiotiche contemporanee: Il concetto di testo nel "Discorso su Dante" di Mandelstam". Autografo. Quadrimestrale de Centro di Ricerca sulla Tradizione Manoscritta di Autori Contemporanei 2, Università di Pavia (1984), 3-6.

- (1983). «Der Einfluss im kulturellen Feld». Wiener Slawistischer Alm. 12 (1983), 5-19.

- (L, 1983). «L'Ode di Lomonosov ispirata al libro di Giobbe». En Lotman, La semiosfera, 1985, 147-164; y con el título «Sull" "Ode scelta da Giobbe" di Lomonosov», Rassegna sovietica 36, 3 (1985), 3-16.

- (T, 1983a). «Una teoria del rapporto reciproco fra le culture (da un punto di vista semiotico)». En Lotman, La semiosfera, 1985, 113-129. «Zum Aufbau der Theorie der Kulturwechselwirkung (Semantischer Aspekt)», Proceedings of the $X$-th Congress of the International Comparative Literature Association, New York 1982, New York/London, 1985, Vol. I, General Problems of Literary History, 16-20.

- (T, 1983b). «L'asimmetria e il dialogo». En Lotman, La semiosfera, 1985, 91-110.

- (T, 1983c). «Tjučev e Dante». Autografo. Quadrimestrale de Centro di Ricerca sulla Tradizione Manoscritta di Autori Contemporanei 2, Università di Pavia (1984), 6-9.

- (1984a). «Bachtin -sein Erbe und aktuelle Probleme der Semiotik». En Roman und Gesellschaft, Wissenschaftliche Beitrage der Fr. Schiller, Universidad de Jena, 1984, 32-40. 
- (1984b). «Mensch, Dingwelt und Raum: Gedanken zur Ausstellung "Das Stilleben und sein Gegenstand"». Dresdener Kunstblätter 2 (Dresden, 1984), 57-62.

- (1984c). «"Agreement" and "Self-Giving" as Archetypal Models of Culture». En Shukman, ed. (1984), 141-164.

- (1984d). «The Stage and Painting as Code Mechanismus for Cultural Behavior in the Early Nineteenth Century». En Shukman, ed. (1984), 165-176.

- (1984e). «Gogol's Chlestakov: The Pragmatics of a Literary Character». En Shukman, ed. (1984), 177-212.

- (1984f). «La cultura e l'organismo». En Lotman, La semiosfera, 1985, 77-82.

- (1984g). «La Metasemiotica e la struttura della cultura». En Lotman, La semiosfera, 1985, 83-90.

- (1984j). «La dinamica dei sistemi culturali». En Lotman, La semiosfera, $1985,131-145$.

- (1984k; T, 1986). «Il diritto alla biografia. Il rapporto tipologico fra il testo e la personalità dell'autore». En Lotman, La semiosfera, 1985, 181-199.

- (T, 1984a) «Acerca de la semiosfera». Criterios 30 (1991), 3-22; y en Criterios, edición especial (1993), 133-150. «La semiosfera», en Lotman, La semiosfera, 1985, 55-76. «Über die Semiosphäre», Studia Russica Helsingiensia et Tartuensia. Slavica Helsingiensia 6 (Helsinki, 1989), 7-24; y en Zeitschrift für Semiotik 12/4 (1990), 287-305.

- (T, 1984b). «Símbolos de Petersburgo y problemas de semiótica urbana». Revista de Occidente, 155 (1994), 5-22. «Il simbolismo di Pietroburgo e i problemi della semiotica della città», en Lotman, La semiosfera, 1985, 225 243. «St. Peterburg: Die Symbolik der Stadt und ihre Dechiffrierung», Europas Kulturzeitung. Lettre International 15 (1991), 32-35.

- (M, 1985). «Über biographische Literatur». Kunst und Literatur 3, 5 (1985), 603-612.

- (D, 1986). «The Transformation of the Tradition Generated by Onegin in the Subsequent History of the Russian Novel». Russian Views of Pushkin's Eugene Onegin, Bloomington, 1988, 169-177.

- $(\mathrm{T}, 1986)$. «On the Contemporary Concept of the Text». Livstegn. Journal of the Norsk Forening for Semiotikk/Norwegian Association for Semotic Studies. Proceedings of the First Symposium "Semiotics in Theory and Practice", Bergen (Norway), 2-3 Oct. 1986, 3 (1987), 155-163.

- (1987a; T, 1989). «Sobre el papel de los factores casuales en la evolución literaria». Discurso. Revista Internacional de Semiótica y Teoría Literaria 8 (1993), 91-101. «Zur Rolle der zufälligen Faktoren in literarischer Evolution», en Broms y Kaufmann, eds. (1987), 139-150.

- (1987b). «Semiotics and Culture in the Second Half of the Twentieth Century». Livstegn. Journal of the Norsk Forening for Semiotikk/Norwegian Association for Semotic Studies. Proceedings of the First Symposium "Semiotics in Theory and Practice", Bergen (Norway), 2-3 Oct. 1986, 3 (1987), 7-11.

- (1987c). «Che cos'è un testo?». Lettera internationale 12 (1987), 37.

- (1987d). «Le mot et la langue dans la culture du Siècle des Lumières». Septième Congrès International des Lumières. Budapest, 26 juillet- 2 août 1987, Budapest, 1987, 255-262.

- (1987e). «Les grandes idées des lumières». Début et fin des lumières en Hongrie, en Europe Centrale et en Europe Orientale. Actes du Sixième Colloque de Mátrafüred, 20-25 oct. 1984, Budapest/Paris, 1987, 155-166. 
- (1987f). «La novita della leggenda». Rassegna sovietica 40, 2 (1989), 57-63.

- (1987g). «Sobre las paradojas de la redundancia: el lenguaje artístico y la historia». Archipiélago 1 (1988), 43-50.

- (M, 1987). «Algunas consideraciones sobre la tipología de las culturas». Revista de Occidente 103 (1989), 5-19; y en Eutopias, $2^{a}$ época, Documentos de trabajo, Vol. 11 (1993), Valencia: Centro de Semiótica y Teoría del espectáculo de la Universitat de València, 16 páginas. "Alcune considerazioni sulla tipologia delle culture», Uomo e Cultura. Rivista di studi antropologici 37/40 (Palermo, 1987), 3-16.

- (T, 1987). «El símbolo en el sistema de la cultura». Escritos. Revista del Centro de Ciencias del Lenguaje 9 (Puebla, México, 1993), 47-60.

- (1988a). «Informazione e giudizio: i compiti del recensore». L'Indice dei libri del mese 8 (1988), 25-26.

- (1988b). «Klio am Scheiderweg». Kopfbahnof 2 (Leipzig, 1990), 135-147.

- (1988c). «Natural Environment and Information». Lectures in Theoretical Biology, Tallinn, 1988, 45-47.

- (T, 1988). «Technological Progress as a Problem in the Study of Culture». Poetics Today 12, 4 (1991), 781-800.

- (1991a). «Proposition relative au projet d'un "Dictionnaire des symboles au siècles des Lumières"». Neohelicon. Acta comporationes litterarum universarum 18, 1 (Budapest/Amsterdam, 1991), 25-30.

- (1991b). «Semiotics and the Historical Sciences». Dialogue and Technology: Art and Knowledge, London, [The Springer Series of Artificial Intelligence and Society], 1991, 165-180.

- (1992a). «La memoria a la luz de la culturología». Criterios 31 (La Habana, 1994), 223-228.

- (1992b). «La modernidad entre la Europa del Este y del Oeste». En Investigaciones Semióticas V. Semiótica y Modernidad. Actas del V Congreso Internacional de la Asociación Española de Semiótica (Celebrado en La Coruña, 3-5 de diciembre de 1992), A Coruña: Universidade da Coruña/Asociación Española de Semiótica, 1994, Volumen I, 69-77.

- (T, 1992). «Sobre la dinámica de la cultura». Discurso. Revista Internacional de Semiótica y Teoría Literaria 8 (1993), 103-121.

\subsection{Trabajos en colaboración}

I. M. Lotman y B. M. Gasparov (1979). "La rhétorique du non verbal». Rhétoriques, sémiotiques. Revue d'Esthétique 1/2 (1979), 75-95.

I. M. LotMAN y Z. G. MiNTS (T, 1981). «Literatura y mitología». Criterios 30 (La Habana, 1991), 30-50. «Letteratura e mitologia», en Lotman, La semiosfera, 1985, 201-224.

- (T, 1983). «La saffigurazione degli elementi naturali nella letteratura». Autografo. Quadrimestrale de Centro di Ricerca sulla Tradizione Manoscritta di Autori Contemporanei 2, Università di Pavia (1984), 9-16.

I. M. LOTMAN y N. N. NikolaENKo (T, 1983). «Dialogo degli emisferi cerebrali». Alfabeta 59 (Milano, 1984), 21-23.

I. M. Lotman y A.M. Piatigorski (T, 1968). «Le texte et la fonction». Semiotica 1, 2 (1969), 205-217. «Text and Function», en Lucid, ed. (1977), 125-135; y en New Literary History 9, 2 (1978), 233-244. «Text und Funktion», Textsemiotik als Ideologiekritik, Frankfurt, 1977, 149-164. 
I. M. Lotman, N. I. TOlSTOI y B. A. UsPenski (T, 1981). «I monumenti letterari russi del XVIII secolo: alcuni problemi di redazione dei testi», Rassegna sovietica, 34, 3 (1983), 21-37.

I. M. LotMAN y B. A. USPENSKI (T, 1971). «Acerca del mecanismo semiótico de la cultura». Santiago. Revista de la Universidad de Oriente 13/14 (Santiago de Cuba, Dic. 1973-Mar. 1974), 109-140; y en Lotman y Escuela de Tartu (1979), 67-92. «The Sign Mechanism of Culture», Semiotica 12, 4 (1974), 301-305; New Literary History 9, 2 (1978), 211-232. «Sul meccanismo semiotico della cultura", en Lotman y Uspenskij (1975), 39-68; y en Lotman y Uspenskij (1975a), 59-95. «Zum semiotischen Mechanismus der Kultur», en Eimermacher, ed. (1986), 853-880.

- (1973). «Introduzione», a Lotman y Uspenskij, eds. (1973), XI-XXVII.

- (T, 1973). «Mito, nombre, cultura». En Lotman y Escuela de Tartu (1979), 111-135. «Myth-Name-Culture», en Baran, ed. (1974), 3-32; en Soviet Studies in Literature: A Journal of Translations XI, 2/3 (1975), 17-46; en Lucid, ed. (1977), 233-252; y en Semiotica 22, $3 / 4$ (1978), 211233. «Mito-Nome-Cultura», en Lotman y Uspenskij (1975), 83-109; y en Lotman y Uspenskij (1975a), 97-131. «Mythe-Nom-Culture», en Lotman y Ouspenski, eds. (1976), 18-39. «Mythos-Name-Kultur», en Eimermacher, ed. (1986), 881-907.

- (L, 1977). «Neue Aspekte bei der Erforschung der Kultur der Alten Russian». Kunst und Literatur I (1978), 81-90. «Nuovi aspetti nello studio della cultura dell'antica Rus'», Strumenti Critici 42/43 (Torino, 1980), 347-371; y en D'Arco Silvio Avalle (a cura di), La cultura nella tradizione russa del XIX e XX secolo, Torino: Einaudi («Paperbacks»), 1982, 219-241. «New Aspects in the Study of Early Russian Culture», en Shukman, ed. (1984), 36-52.

- (T, 1977). «Die Rolle dualistischer Modelle in der Dynamik der russischen Kultur (bis zum Ende 18.Jahrhunderts)». Poetica. Zeitschrift für Sprach- und Literaturwissenschaft 9, 1 (1977), 1-40. «Il ruolo dei modelli duali nella dinamica della cultura russa (fino alla fine del XVIII secolo)", Strumenti Critici $42 / 43$ (1980), 372-416; y en D'Arco Silvio Avalle (a cura di), La cultura nella tradizione russa del XIX e XX secolo, Torino, Einaudi («Paperbacks»), 1982, 242-286. «The Role of Dual Models in the Dynamics of Russian Culture (Up to the End of the Eighteenth Century)», en Shukman, ed. (1984), 3-35; y, con el título «Binary Models in the Dynamics of Russian Culture (to the End of the Eighteenth-Century)», en Nakhimovski, A. D. y Stone, A., eds. (1985), 30-66.

- (1979). «Postscriptum alle tesi collettive sulla semiotica della cultura». En Prevignano, ed. (1979), 221-224.

- (M, 1982). «Echoes of the Notion "Moscow as the Third Rome" in Peter the Great's Ideology». En Shukman, ed. (1984), 53-67. «Il concetto di "Mosca Terza Roma" nell' ideologia di Pietro I', Europa Orientalis 5 (1986), 481-494.

- (T, 1982). «Il "degradato" e il "degradamento" come condizione sociopsicologica nella cultura russa precedente al regno di Pietro I». En Lotman, La semiosfera, 1985, 165-180.

I. M. Lotman, V. V. Ivanov, A. M. Piatigorski, A. M. Toporov y B. A. USPENSKI (V, 1973). «Theses on the Semiotic Study of Cultures (as Applied to the Slavic Texts)». En Van der Eng y Grygar, eds. (1973), 1-28; en The Tell-Tale Sign: A Survey of Semiotics (ed. T. A. Sebeok), Lisse: 
Peter de Ridder, 1975, 57-83; y en Publications in Semiotics of Culture, 2, Lisse: Peter de Ridder Press, 1975, 29 páginas. «Thèses pour l'étude sémiotique des cultures (en application aux textes slaves)», Sémiotique. Recherches internationales à la lumière du marxisme 81, 4 (Paris, 1974), 125-156. «Tesi per un analisi semiotica della cultura (in applicazione ai testi slavi)», en Prevignano, ed. (1979), 194-220; y con el título Tesi sullo studio semiotico della cultura, Parma: Pratiche, 1980. «Thesen zur semiotischen Erforschung der Kultur (In Anwendung auf slawische Texte)», en Eimermacher, ed. (1986), 85-115.

\subsection{Entrevistas}

- (1972). «Secondo questionario. Risposte». Bianco e nero. Strutturalismo e critica del film 3/4 (Roma, 1972), 27-28.

- (1987). «Greetings to the Symposium. An Interview with Yuri Lotman in Helsinki, June 1987». En Broms y Kaufmann, eds. (1987), 115-123.

- (M, 1987). «Kulturgeschichte zukunftsorientiert (Interview mit T. Men'sikova für Svetskaja Kul'tura, 17.5.1987)». Gesellschaftswissenschaften. Zeitschrift der Sektion Gesellschaftswissenschaften der Akademie der Wissenschaften der UdSSR 3 (1988), 167-174. «L'histoire de la culture: cheminement vers le futur», Sciences sociales 2, 72 (Moscou, 1988), 155-161.

- (R, 1987). «Gespräch mit Juri Lotman über den Film». Kunst und Literatur. Sowjetwissenschaften 36, 2 (Jahr. 1988), 192-198.

- (1988). «La convivenza dei linguaggi. J. Lotman». Leggere 4 (1988).

- (1990). «Sechs Fragen zur semiotischen Analyse von Kultur [Gesprächt mit Roland Posner]». Zeitschrift für Semiotik 12, 4 (1990), 375-380.

- (1993). «Peeter Torop conversa con Iuri Lotman». Discurso. Revista Internacional de Semiótica y Teoría Literaria 8, 123-137.

\section{BIBLIOGRAFÍA DE LA ESCUELA SEMIÓTICA DE TARTU- MOSCÚ}

Averintsev, S. S. (T, 1974). «El carácter general de la simbólica en la Alta Edad Media». En Lotman y Escuela de Tartu (1979), 145-148. «Le caractère général de la symbolique au Haut Moyen Age», en Lotman y Ouspenski, eds. (1976), 152-155.

- (M, 1986). «La movilidad histórica de la categoría de género: un intento de periodización». Criterios 25/28 (La Habana, 1990), 208-220.

BILINkis, M. Y. y Tourovski, A. M. (T, 1968). «A propos d'un texte hermétique». En Lotman y Ouspenski, eds. (1976), 202-204.

Bogatirev, P. G. (T, 1968). «O scénario, o espaço artístico e o tempo no teatro popular». En Schnaiderman, ed. (1979), 243-248.

Chernov, I. (1972). «Tres modelos de la cultura». Criterios 2 (La Habana, 1982), 107-120.

- (1991). «National Literature: Theoretical Marginalia». Poetics Today 12, 4 (1991).

CIV'JAN, T. V. (M, 1962a). «La communicazione gestuale e il suo posto tra gli altri sistemi della communicazione umana». En Faccani y Eco, eds. (1969), 261-272. 
- (M, 1962b). «Etiquette as a Semiotic System». En Lucid, ed. (1977), 103-105.

- (1973). «La semiótica del comportamiento humano en situaciones dadas (principio y fin de la ceremonia, fórmulas de cortesía)». En Lotman y Escuela de Tartu (1979), 173-194. «La semiotica del comportamento in situazioni fisse (inizio e fine della situazione d'etichetta)», en Lotman y Uspenskij, eds. (1973).

CiV'JAN, T. V. y SEGAL, D. M. (T, 1965). «Struttura dela poesia inglese del "nonsense" (sulla base dei limericks di E. Lear)». En Faccani y Eco, eds. (1969), 151-162; y en Eco y Faccani, eds. (1969), 123-134.

Egorov, B. F. (M, 1964). «Struttura del racconto di Cechov "Dom s mezaninom"». En Lotman y Uspenskij, eds. (1973), 318-334.

- (T, 1965). «Simplest Semiotic Systems and Plot Tipology». Semiotica 10, 2 , 1974, 131-137; y en Lucid, ed. (1977), 77-86. «I sistemi semiotici più simplici e la tipologia degli intrecci», en Faccani y Eco, eds. (1969), 249-260.

Elizarenkova, T. I. (T, 1974). «Pour une structure du charme dans l'Atharvaveda». En Lotman y Ouspenski, eds. (1976), 73-76.

ElizARENKOVA, T. I. y TOPOROV, V. N. (T, 1970). «Les représentations mythologiques touchant aux champignons dans leurs rapports avec l'hypothèse de l'origine du Soma». En Lotman y Ouspenski, eds. (1976), 62-68. «Concepções mitológicas sobre os cogumelos, relacionadas com a hipótese do caráter primitivo do soma», en Schnaiderman, ed. (1979), 61-67.

Fortunatov, N. M. (L, 1970). «O ritmo da prosa literária». En Schnaiderman, ed. (1979), 219-220.

FreidenberG, O. M. (T, 1973). «The Origin of Parody». En Baran, ed. (1974), 269-283.

Gasparov, B. M. (1976). «Some Descriptive Problems of Musical Semantics». Dispositio 1, 3 (1976), 247-262.

- (T, 1976). «The Narrative Text as an Act of Communication». New Literary History 9, 2 (1978), 245-261.

- (1979). Vid. LOTMAN y GASPAROV (1979).

Gasparov, B. M., Gasparova, E. M. y MinTs, Z. G. (T, 1971). «A Statistical Approach to Analyzing the Content Plane of the Belles-Lettres Text». Linguistics 121 (1974), 21-43.

GASPAROV, M. L. (T, 1979). «M.M. Bajtín en la cultura rusa del siglo XX». Criterios (edición especial), La Habana/México, Casa de las Américas/UNEAC/Universidad Autónoma Metropolitana Xochimilco (1993), 19-22.

GiNGSBURG, L. I. (L, 1971). «The "Human Document" and the Formation of Character». En Nakhimovski, A. D. y Stone, A., eds. (1985), 188-224.

GlazOV, J. J. (T, 1966). «La famiglia monogamica come struttura di segni». En Faccani y Eco, eds. (1969), 365.

GuREVICH, A. I. (T, 1987). «El portal occidental de la iglesia de Saint-Lazare en Autun y las paradojas de la conciencia medieval». Escritos. Revista del Centro de Ciencias del Lenguaje 9 (Puebla, México, 1993), 161-172.

IVANOV, V. V. (M, 1961). «Cybernetics and the Science of Language». Modern Language Journal 46, 4 (1962), 158-159.

- (M, 1962a). «La semiotica e le scienze umanistiche». Questo e altro 6/7 (1964), 57-59.

- (M, 1962b). «The Science of Semiotics». New Literary History 9, 2 (1978), 199-204. 
- (M, 1962c). «A Lingüística e o estudo da afasia». En Schnaiderman, ed. (1979), 263-304.

- (M,1962d). Vid. ZALIZNJAK, IVANOV y Toporov (M, 1962).

- (M, 1964). The Psicology of Art. Cambridge (Mass.): MIT Press, 1971.

- (M, 1965). «La función de la semiótica en la investigación cibernética del hombre y de la colectividad». En Comunicación, ed. (1972), 17-34. «Ruolo della semiotica nell'indagine cibernetica dell'uomo e della collectività», en Faccani y Eco, eds. (1969), 41-54. «The Role of Semiotics in the Cybernetic Study of Man and Collective», en Lucid, ed. (1977), 27-38.

- (T, 1967). «Structure d'un poème de Khlebnikov». Tel Quel 35 (1968), 9-23. «The Structure of Khlebnikov's Poem "Menya pronosyat na slonovykh"», en O'Toole y Shukman, eds. (1975-1976), 2, 34-46.

- (T, 1968a). «L'asymétrie des oppositions sémiotiques universelles». En Lotman y Ouspenski, eds. (1976), 52-53.

- (T, 1968b). «Caractéristiques numériques de la mythologie et des rites romains». Tel Quel 35 (1968), 35-37.

- (1969). «Evolution des signes-simboles». Semiotica 1, 2 (1969), 218-221.

- (L, 1970). «O papel das oposições binárias na abordagem mitopoética do tempo». En Schnaiderman, ed. (1979), 221-223.

- (T, 1970). «La estructura de los signos en el cine». En Lotman y Escuela de Tartu (1979), 219-224. «La structure des signes au cinéma», en Lotman y Ouspenski, eds. (1976), 175-180. «Sobre a estrutura dos signos no cinema», en Schnaiderman, ed. (1979), 255-260.

- (1971). «À propos de la religion romaine archaïque par G. Dumézil». En Kristeva y otros (1971), 327-334.

- (1973a). «La semiótica de las oposiciones mitológicas de varios pueblos». En Lotman y Escuela de Tartu (1979), 149-172. «La semiotica delle opposizioni mitologiche di vari popoli», en Lotman y Uspenskij, eds. (1973).

- (1973b). «On Binary Relations in Linguistic and Other Semiotic and Social Systems». En R. J. Bodgan (ed.), Logic, Language and Probability. Dordecht: Riedel, 196-200.

- (L, 1973). «The Category of Time in 20th-Century Art and Culture». Semiotica 1 (1973), 1-45.

- (T, 1973a). «La catégorie "visible"-"invisible" dans les textes des cultures archaïques». En Lotman y Ouspenski, eds. (1976), 58-61.

- (T, 1973b). «The Signifiance of M. M. Baxtin's Ideas on Sign, Utterance, and Dialogue for Modern Semiotics». En Baran, ed. (1974), 310-367.

- $(\mathrm{V}, 1973 \mathrm{a})$. «La traduction poétique à la lumière de linguistique». Change 14 (Paris, 1973).

- (V, 1973b) Vid. LotMAN, IVANOV, PiATIGORSKI, TOPOROV y USPENSKI $(\mathrm{V}, 1973)$.

- (1974). «Growth on the Theoretical Framework of Modern Poetics». En T. A. Sebeok (ed.), Current Trends in Linguistics, Vol. 12, The Hague/Paris: Mouton, 1974, 835-884.

- $(T, 1974 a)$. «Les relations antisymétriques et symétriques dans les langues naturelles et dans d'autres systèmes sémiotiques». En Lotman $y$ Ouspenski, eds. (1976), 12-17. «On Antisymmetrical and Asymmetrical Relations in Natural Languages and Other Semiotic Systems», Linguistics 119 (1974), 35-40. 
- (T, 1974b). «Restoration of the Original Text of the Ket Myth about the Destroyer of Eagles' Nest». En Baran, ed. (1974), 226-243.

- (1977). «Doctor Faustus («Il problema fondamentale» nella teoria dell'arte di S.M. Ejzenštejn)». En D'Arco Silvio Avalle (a cura di), La cultura nella tradizione russa del $X I X$ e $X X$ secolo, Torino: Einaudi («Paperbacks»), 1982, 317-356.

- (T, 1977). "Contribución a la teoría semiótica del carnaval como inversión de oposiciones binarias». Criterios 29 (La Habana, 1991), 35-58. «The Semiotic Theory of Carnival as the Inversion of bipolar opposites», en T. Sebeok, ed. (1984), Carnival!, New York: Mouton, 11-35.

- (1978). The Structure of the Ket Myth of the "Dénicheur des Anglons" and its American Indian Parallels. Urbino: Centro Internazionale di Semiotica e di Linguistica/Working Papers and Pre-publications, 78-79 (Nov.-Dec. 1978).

— (T, 1981). «El filme en el filme». Criterios, edición especial (1993), 151-164.

- $(\mathrm{T}, 1986)$. «Contribución al estudio semiótico de la historia cultural de la gran ciudad». Escritos. Revista del Centro de Ciencias del Lenguaje 9 (Puebla, México, 1993), 107-127.

IVANOV, V. V. y TOPOROV, V. N. (T, 1965). «Towards the Description of Ket Semiotics Systems». Semiotica 9 (1973), 318-346.

- (M, 1975). «The Invariant and Transformations in Folklore Texts». Dispositio 1,3 (1976), 263-270.

- (T, 1977). «El enfoque tipológico-estructural de la interpretación semántica de las obras de artes plásticas en el aspecto diacrónico». Escritos. Revista del Centro de Ciencias del Lenguaje 9 (Puebla, México, 1993), 85-105.

KARPINSKAJA, O. G. y REvZIN, I. I. (T, 1966). «A Semiotic Analysis of Early Plays by Ionesco (The Bald Soprano, The Lesson)». En Lucid, ed. (1977), 199-202. «Análise semiótica das primeiras peças de Ionesco ("A cantora careca" e "A lição")», en Schnaiderman, ed. (1979), 249-252.

Kolmogorov, A. N. y Kondratov, A. M. (1962). «Ritmica dei poemetti di Majakovskij». En Eco y Faccani, eds. (1969), 139-167.

LANGLEBEN, M. M. (T, 1965). «Descrizione del sistema della notazione musicale». En Faccani y Eco, eds. (1969), 287-304.

- (T, 1968). «La musica e il linguaggio naturale». En Faccani y Eco, eds. (1969), 283-286.

LEKOMCEV, J. K. (T, 1967). «El aspecto semiótico del arte figurativo». En Comunicación, ed. (1972), 73-83. «L'aspetto semiotico dell'arte figurativa», en Faccani y Eco, eds. (1969), 202-210.

- (T, 1973). «Foundations of General Semiotics». En Lucid, ed. (1977), 39-44. «Quelques fondements de la sémiotique générale», en Lotman y Ouspenski, eds. (1976), 236-242.

LEKOMCEVA, M. I. y USPENSKIJ, B. A. (T, 1965a). «La cartomanzia come sistema semiotico». En Faccani y Eco, eds. (1969), 243-247.

- (T, 1965b). «Describing a Semiotic System with a Simple Syntax». En Lucid, ed. (1977), 65-76.

LEVIN, I. I. (T, 1965). «The Structure of the Metaphor». En Lucid, ed. (1977), 203-209.

- (T, 1973). «La lírica desde el punto de vista comunicativo». Criterios 1320 (La Habana, 1985-1986), 101-119. «Le statut communicatif du poème lyrique», en Lotman y Ouspenski, eds. (1976), 205-212. 
- (T, 1981). «Tesis sobre el problema de la no comprensión del texto». Escritos. Revista del Centro de Ciencias del Lenguaje 9 (Puebla, México, 1993), 143-159.

LEVINTON, G. A. (T, 1970). «Algumas questões gerais no estudio do rito matrimonial». En Schnaiderman, ed. (1979), 73-80.

MALL, L. (T, 1967). «Une approche possible du Sunyavada». Tel Quel 35 (1968), 54-62.

MAYENOWA, M. R. (1973). «An Analysis of Some Visual Signs: Suggestions for Discussion». En Eng y Grygar, eds. (1973), 197-208.

MEIJER, J. M. (1973). «Verbal Art as Interference between a Cognitive and an Aesthetic Structure». En Eng y Grygar, eds. (1973), 313-348.

MEJLAX, M. B. (T, 1973). «The Structure of the Courtly Universe of the Troubadours». Semiotica 14, 1 (1975), 61-80.

MELETiNSKi, E. M. (M, 1969). «El estudio estructural y tipológico del cuento». En V. Propp, Morfología del cuento (trad. de la versión francesa), Madrid: Akal, 1985, 221-275. «Structural-Typological Study of the Folktales», en Maranda, ed. (1974), 19-51; y en Genre 4, 249-279. «L'étude structurale et typologique du conte», en V. Propp, Morphologie du conte, París, 1970.

- (1970). «Problem of the Historical Morphology of the Folktale». En Maranda, ed. (1974), 53-59.

- (M, 1970). «Marriage: Its Function and Position in the Structure». En Maranda, ed. (1974), 61-72.

- (M, 1972). «Primitive Sources of Verbal Art». En Baran, ed. (1974), 87-152.

- (1974). «A Structural-Typological Analysis of Paleo-Asiatic Mythology». En Baran, ed. (1974), 153-183.

- (M, 1974). «Tipologia estrutural e folclore». En Schnaiderman, ed. (1979), 43-59.

- (M, 1976). «Il “mitologisno" di Kafka». En D’Arco Silvio Avalle (a cura di), La cultura nella tradizione russa del XIX e XX secolo, Torino: Einaudi («Paperbacks»), 1982, 359-381.

- (T, 1983). «La organización semántica del relato mitológico y el problema del índice semiótico de motivos y sujets». Escritos. Revista del Centro de Ciencias del Lenguaje 9 (Puebla, México, 1993), 129-141.

MeletinskiJ, E. M., Nekluudov, S. J., Novik, E. S. y Segal, D. M. (T, 1969). «Problems of Structural Description of Fairytales». En Maranda, ed. (1974), 73-139.

MinTS, Z. G. (T, 1969). «Struttura compositiva del ciclo di A. Blok "Snjeznaja maska"». En Lotman y Uspenskij, eds. (1973), 251-317 (trad. parcial).

- (T, 1971). Vid. Gasparov, Gasparova y MinTs (T, 1971).

- (T, 1974). «El concepto de texto y la estética simbolista». En Lotman y Escuela de Tartu (1979), 137-144. «Le concept de texte et l'esthétique symboliste», en Lotman y Ouspenski, eds. (1976), 222-229.

- (T, 1981). Vid. LotMAN y MiNTS $(\mathrm{T}, 1981)$.

- (T, 1983). Vid. LOTMAN y MinTs (T, 1983).

NeKLIOUdOV, S. Y. (T, 1966). «Le problème de la liaison des relations spatiotemporelles avec la structure du sujet dans la byline russe». En Lotman y Ouspenski, eds. (1976), 193-196.

- (T, 1969). Vid. MeletinskiJ, Nekluddov, NoviK y Segal (T, 1969).

- (M, 1972). «Il sistemi spaziale nell'intreccio della bylina russa». En Lotman y Uspenskij, eds. (1973), 107-124 (Abreviado).

Nikolaenko, N. N. (T, 1983). Vid. Lotman y Nikolaenko (T, 1983). 
Novik, E. S. (T, 1969). Vid. MeletinskiJ, NekLJudov, Novik y SEgAL $(\mathrm{T}, 1969)$.

Permuakov, G. L. (1967). «The Logico-Semiotic Level of Proverbs and Sayings (Toward a Classification of the Genre)». En O'Toole y Shukman, eds. (1975-1976), 3.

PJATIGORSKIJ, A. M. (T, 1965). «Some General Remarks on Mythology from a Psychologist's Point of View». Semiotica 10, 3 (1974), 221-232.

- ( $\mathrm{T}, 1967)$. «Personological Classification as a Semiotic Problem». Semiotica 15, 2 (1975), 99-120.

- $(\mathrm{T}, 1968)$. Vid. LotMAN Y Piatigorski $(\mathrm{T}, 1968)$.

- (T, 1970). «O mundo dos símbolos da antigua cultura budista». En Schnaiderman, ed. (1979), 69-71.

- $(T, 1973)$. «Quelques prémisses théoriques de la sémiotique». En Lotman y Ouspenski, eds. (1976), 243-246.

- (V, 1973). Vid. LOTMAN, IVANOV, PIATIGORSKI, TOPOROV y USPENSKI (V, 1973).

- (1977). «"If I Were You" (a Few Remarks About Culture and Understanding)». Russian Literature 5, 2 (1977), 37-40.

- (1987). «Three Origins of Religious Symbolism». En Broms y Kaufmann, eds. (1987) 59-65.

PJATIGorskiJ, A. M. y UsPenskiJ, B. A. (T, 1967). «The Classification of Personality as a Semiotic Problem». En Lucid, ed. (1977), 137-156.

RevZIN, I. I. (T, 1964). «Notes on the Semiotic Analysis of Detective Novels: With Examples from the Novels of Agatha Christie». New Literary History 9, 2 (1978), 385-388.

- (T, 1966). Vid. KARPINSKAJA y REVZIN (T, 1966).

- (1969). «De la lingüística estructural a la semiótica». En Comunicación, ed. (1972), 35-56. «Della linguistica strutturale alla semiotica», en Eco y Faccani, eds. (1969), 27-44.

- (T, 1970). «Language as a Sign System and the Game of Chess». En Lucid, ed. (1977), 87-92.

- $(\mathrm{T}, 1974)$. «Une approche sémiotique du concept de "grande collectivité"». En Lotman y Ouspenski, eds. (1976), 40-43. «A Semiotic Approach to the Concept of the "Large Collective"», en Lucid, ed. (1977), 223-226.

- (1979). «O problema da mensuração da criação artística». En Schnaiderman, ed. (1979), 225-231.

ReVzIN, I. I. y REVZINA, O. G. (T, 1971). «Expérimentation sémiotique chez Eugène Ionesco (La cantatrice chauve et La lesson)». Semiotica 4 (1971), 240-262.

- (T, 1973). «Toward Formal Analysis of Plot Construction». En Baran, ed. (1974), 244-256.

- (1978). «Structural Analysis of a Poem by Rilke». New Literary History 9, 2 (1978), 381-384.

SCEGLOV, J. K. (M, 1962a). «Per la costruzione di un modello strutturale delle novelle di Sherlock Holmes». En Faccani y Eco, eds. (1969), 129-131.

- (M, 1962b). «Alcuni tratti strutturali delle "Metamorfosi" di Ovidio". En Faccani y Eco, eds. (1969), 133-150; en Eco y Faccani, eds. (1969), 105-122; y en Lingua e Stile 4 (1969), 53-68. «Some Features of the Structure of Ovid's "Metamorphoses"», en O'Toole y Shukman, eds. (1975-1976), 2, 50-65. "Algumas características da estrutura de As Metamorfoses de Ovídio», en Schnaiderman, ed. (1979), 131-138. 
- (V, 1968). «Toward a Description of Detective Story Structure». En O'Toole y Shukman, eds. (1975-1976), 1, 51-77.

- (M, 1971). Vid. ZolkovSKIJ y SCEGLOV (M, 1971).

- (1972). Vid. ZOLKOVSKIJ y SCEGLOV (1972).

Segal, D. M. (M, 1962). «Problems in the Semiotic Study of Mithology», en Lucid, ed. (1977), 59-64.

- (T, 1965). Vid. Civ'JAN y SEgaL (T, 1965).

- (V, 1966). «La conexión entre la semántica y la estructura formal del texto». En Comunicación, ed. (1972), 119-159. «The Connection between the Semantics and the Formal Structure of a Text», en P. Maranda (ed.), Mythology, Harmondsworth: Penguin, 1972, 215-249. «Sobre a relação da semântica do texto com sua estrutura formal», en Schnaiderman, ed. (1979), 97-128.

- (T, 1968). «O problema do substrato psicológico do signo e algumas concepções teóricas de S. M. Eisenstein». En Schnaiderman, ed. (1979), 235-240.

- (T, 1969) Vid. Meletinskij, Nekluudov, Novik y Segal (T, 1969).

SYRKIN, A. J. (T, 1967). «Notes on the Kamasutra». Semiotica 11, 1 (1974), 33-42.

- (1981). «Alive-Not Alive (Some Aditional Notes)». Slavica Hierosolymitana 5-6 (1981).

SYRKIN, A. J. y Toporov, V. N. (T, 1968). «La triade et la tétrade». Tel Quel 35 (1968), 27-32.

TOlSTOI, N. I. (T, 1981). Vid. LotMAN, Tolstoi y USPENSKI (T, 1981).

TOlSTOI, N. I. y TOLSTOI, S. M. (T, 1974). «Para una semántica de los lados izquierdo y derecho en sus relaciones con otros elementos simbólicos». En Lotman y Escuela de Tartu (1979), 195-198. «Pour une sémantique des côtés gauche et droit dans leurs rapports avec d'autres éléments symboliques», en Lotman y Ouspenski, eds. (1976), 69-72.

Toporov, V. N. (M, 1962). Vid. ZalizNJAK, IVANOV y Toporov (M, 1962).

- (T, 1964). «Le strutture dei livelli inferiori in poesia». En Eco y Faccani, eds. (1969), 85-100.

- (T, 1965a). «Remarques sur les arts plastiques bouddhiques dans leurs rapports avec le problème de la sémiotique des conceptions cosmologiques». En Lotman y Ouspenski, eds. (1976), 158-167.

- (T, 1965b). «On the Semiotics of Predictions in Suetonius's "The Lives of the Twelve Caesars"». En O'Toole y Shukman, eds. (1975-1976), 2, 22-33; y en Lucid, ed. (1977), 157-167.

- (T, 1965c). Vid. IVANOV y TOPOROV $(\mathrm{T}, 1965)$.

- (T, 1968). Vid. SYRKIN y TOPOROV $(T, 1968)$.

- (M, 1969). «On the Typological Similarity of Mythological Structures Among the Ket and Neighbouring Peoples». Semiotica 10, 1 (1974), 19-42.

- (T, 1970). Vid. ElizARENKOVA y Toporov (T, 1970).

- (M, 1972). «Toward the Origin of Certain Poetic Symbols: The Paleolitic Period». En Baran, ed. (1974), 184-225.

- (1973). "L'albero universale. Saggio d'interpretazione semiotica». En Lotman y Uspenskij, eds. (1973), 148-209.

- (S, 1973). «On Dostoevsky's Poetics and Archaic Patterns of Mythological Thought». New Literary History 9, 2 (1978), 333-380. «La poetica di Dostoevskij e gli schemi arcaci del pensiero mitologico (Delitto e castigo)», en D'Arco Silvio Avalle (a cura di), La cultura nella tradizione russa del XIX e XX secolo, Torino: Einaudi («Paperbacks»), 1982, 289-314. 
- $(T, 1973)$. «Les sources cosmologiques des premières descriptions historiques». En Lotman y Ouspenski, eds. (1976), 94-140. «On the Cosmological Origins of Early Historical Descriptions», en O'Toole y Shukman, eds. (1975-1976), 3.

- (V, 1973). Vid. LOTMAN, IVANOV, PIATIGORSKI, TOPOROV y USPENSKI (V, 1973).

- (T, 1974). «Toward the Problem of Genres in Folklore». En Baran, ed. (1974), 76-86.

- (M, 1975). Vid. IVANOV y TOPOROV $(\mathrm{M}, 1975)$.

- (T, 1977). Vid. IVANOV y TOPOROV (T, 1977).

- (M, 1979). «The Semantics of Mythological Conceptions of Mushrooms». Semiotica 53, 4 (1985), 295-357.

- (M, 1980). «Las artes plásticas y la mitología». Criterios 21/24 (La Habana, 1989), 180-193.

TOROP, P. (T, 1984). «Simultaneidad y dialogismo en la poética de Dostoievski». Escritos. Revista del Centro de Ciencias del Lenguaje 9 (Puebla, México, 1993), 173-197.

Tourovski, A. M. (T, 1968). Vid. Bilinkis y Tourovski (T, 1968).

USPENSKI, B. A. (M, 1962a). «Sobre la semiótica del arte». En Comunicación, ed. (1972), 167-172. «Sulla semiotica dell'arte», Questo e altro 6/7 (1964), 60-61; en Faccani y Eco, eds. (1969), 87-90; y en Eco y Faccani, eds. (1969), 59-62. «Semiotics of Art», en Lucid, ed. (1977), 171-173.

- (M, 1962b). «La sémiotique chez Chesterton». En Lotman y Ouspenski, eds. (1976), 230-233. «A Semiótica em Chesterton», en Schnaiderman, ed. (1979), 159-162.

- (T, 1965a). Vid. LEKOMCEVA y USPENSKIJ (T, 1965a).

- (T, 1965b). Vid. LEKOMCEVA y USPENSKIJ (T, 1965b).

- (1968). Principles of structural typology. The Hague: Mouton, 80 páginas.

- (T, 1967). Vid. PJATIGORSKIJ y USPENSKIJ (T, 1967).

- (V, 1968). «Structural Isomorphism of Verbal and Visual Art». Poetics 5, 1972, 5-39.

- (T, 1969a). «Los problemas semióticos del estilo a la luz de la lingüística». En R. Barthes y otros, Estructuralismo y literatura, Buenos Aires: Nueva Visión, 1970, 83-106. «Les problèmes sémiotiques du style à la lumière de la linguistique», en Information sur les sciences sociales VII, 1 (1968); y en Kristeva y otros, eds. (1971).

- $(\mathrm{T}, 1969 \mathrm{~b})$. «The Influence of Language on Religious Consciousness». Semiotica 10, 2, 177-189.

- (M, 1970a). Poétique de la composition. Paris: Seuil, 1970. A Poetics of Composition: The Structure of the Artistic Text and Typology of a Compositional Form, Berkeley: University of California Press, 1973, 202 páginas.

- (M, 1970b). «Los "puntos de vista" en el plano de la psicología». Criterios 5/12 (La Habana, 1983-1984), 117-139 (cap. de M, 1970a).

- (M, 1970c). «The Language of Ancient Painting». Dispositio 1, 3 (1976), 219-246.

- (M, 1970d). «Elementos estruturais comuns às diferentes formas de arte. Princípios gerais de organização da obra em pintura e literatura». En Schnaiderman, ed. (1979), 163-218.

- (M, 1970e). «Poétique de la composition. Point de vue: le problème de la dénomination. L'alternance des points de vue interne et externe en tant que marque du cadre dans une oeuvre littéraire». Poétique 9 (1972), 124-134 (trad. parcial de M, 1970a). 
- (T, 1970). «La "correction grammaticale" et la métaphore poétique». En Lotman y Ouspenski, eds. (1976), 218-221.

- (T, 1971a). The Semiotics of the Russian Icon. Lisse: Peter de Ridder, 1976. «Per l'analisi semiotica delle antiche icone russe», en Lotman y Uspenskij, eds. (1973), 337-399 (Abreviado).

- (T, 1971b). Vid. LOTMAN y USPENSKI (T, 1971).

- (1973). Vid. LOTMAN y USPENSKI (1973).

- (T, 1973a). «La "droite" et la "gauche" dans l'art des icônes». En Lotman y Ouspenski, eds. (1976), 168-174. «Left and Right in Icon Painting». Semiotica 3, 1 (1975), 33-39.

- $(\mathrm{T}, 1973 \mathrm{~b})$. «On the Poetics of Xlebnikov: Problems of the Composition». Russian Literature 9 (1975), 81-86.

- (T, 1973c). Vid. LOTMAN y USPENSKI (T, 1973).

- (V, 1973). Vid. LotMan, IVANOV, PIATIGORSKI, TOPOROV y USPENSKI $(\mathrm{V}, 1973)$.

- (T, 1974). «Historia sub especie semioticae». En Lotman y Escuela de Tartu (1979), 209-218. «Historia sub specie semioticae», en Lucid, ed. (1977), 107-115; y en Baran, ed. (1974), 64 y ss. «Historia sub specie semioticae», en Lotman y Ouspenski, eds. (1976), 141-151. «Historia sub specie semioticae», en Storia e Semiotica, 1988, 1-8.

- (L, 1977). Vid. LOTMAN y USPENSKI $(\mathrm{L}, 1977)$

- (T, 1977). Vid. LOTMAN y USPENSKI (T, 1977).

- (1978a). «Semiotics of the Icon: An Interview». PTL. A Journal for Descriptive Poetics and Theory of Literature III/3 (1978), 529-548.

- (1979). Vid. LOTMAN y USPENSKI (1979).

- (T, 1981). Vid. LOTMAN, TOLSTOI y USPENSKI (T, 1981).

- (M, 1982a). Vid. LOTMAN y USPENSKI (M, 1982).

- (M, 1982b). «Tsar and Pretender: Samozvancestro or Royal Imposture in Russia as a Cultural-Historical Phenomenon». En Shukman, ed. (1984), 259-292. "Lo zar e l'impostore. L'impostura in Russia come fenomeno storico-culturale», en Storia e Semiotica, 1988, 81-103.

- (T, 1982). Vid. LOTMAN y USPENSKI $(T, 1982)$.

- (Tal, 1982). «Sul simbolismo del tempo presso gli slavi. Giorni "puri" e "impuri" della settimana». En Storia e Semiotica, 1988, 77-80.

- (B, 1983). «L'aspetto mitologico della fraseologia espressiva russa». En Storia e Semiotica, 1988, 49-76.

- (1984a). «The Syriac Question in Slavonic Literature: Why Should the Devil Speak Syriac?». En Shukman, ed. (1984), 293-294.

- (1984b). «On the Origin of Russian Obscenities». En Shukman, ed. (1984), 295-300.

- (M, 1985). «L'anticomportamento nella cultura della Russia antica». En Storia e semiotica, 1988, 37-48.

- (1988). Storia e Semiotica. Milano: Bompiani, 1988 (Presentazione di Maria Di Salvo, VII-XV; trad. M. Di Salvo y S. Signorini), 156 págs.

- (T, 1988 y 1989). «La Historia y la Semiótica (La percepción del tiempo como problema semiótico)». Discurso. Revista Internacional de Semiótica y Teoría Literaria 8 (1993), 47-89. «Historia y semiótica (La percepción del tiempo como problema semiótico) "Primer artículo"», Escritos. Revista del Centro de Ciencias del Lenguaje 9 (Puebla, México, 1993), 61-84. "Storia e semiotica. La percezione del tempo come problema semiotico» [Primer artículo], en Storia e semiotica, 1988, 9-36. 
- (1993). Storia della lingua letteraria russa. Dall'antica Rus'a Puškin. Bologna: Il Mulino, 1993 (Ed. N. Marcialis). 286 páginas.

ZALIZNJAK, A. A. (M, 1962). «La regolazione del traffico stradale come sistema di segni». En Faccani y Eco, eds. (1969), 305-306.

ZaliznJAK, A. A., IVANov, V. V. y Toporov, N. N. (M, 1962). «Posibilidad de un estudio tipológico-estructural de algunos sistemas semióticos modelizantes». En Comunicación, ed. (1972), 99-117. «Possibilità di uno studio tipologico-strutturale di alcuni sistemi semiotici modellizzanti», en Faccani y Eco, eds. (1969), 319-332. «Structural-Typological Study of Semiotic Modeling Systems», en Lucid, ed. (1997), 47-58. «Sobre a possibilidade de um estudo tipológico-estrutural de alguns sistemas semióticos modelizantes», en Schnaiderman, ed. (1979), 81-96.

ZOLKIEWSKI, S. (1971). «Sociologie de la culture et sémiotique». En Kristeva y otros, eds. (1971), 121-136.

- (1972). «Poétique de la composition». Semiotica 3 (1972), 295-224.

- (1973a). «Des principes de classement des textes de culture». Semiotica VII, 1 (1973), 1-17.

- (1973b). «Des problèmes de la littérature populaire». En Eng y Grygar, eds. (1973), 303-311.

ZolkovskiJ, A. K. (M, 1962). «Sobre la amplificación». En Comunicación, ed. (1972), 173-182. «Dell'amplificazione», en Faccani y Eco, eds. (1969), 1969, 91-98.

- (T, 1965). «Deus ex machina». En Lotman y Ouspenski, eds. (1976), 182-192.

- (M, 1970). «El cuento somalí "La prueba del adivino"». Prohemio I/3 (Madrid, Diciembre 1970), 445-465.

- (M, 1976). «The Literary Text-Thematic and Expressive Structure: An Analysis of Pushkin's Poem "Ya vas Iyubil"», New Literary History 9, 2 (1978), 263-278.

- (1978). «The Window in the Poetic World of Boris Pasternak». New Literary History 9, 2 (1978), 279-314.

- (1983). Themes and Texts: Toward a Poetics of Expressiveness. Ithaca: Cornell University Press, 1983.

ZolkovskiJ, A. K. y ScEglov, J. K. (M, 1971). «La construcción del modelo "Tema [Procedimientos de expresividad] / Texto". I. El concepto de tema y el de universo poético». Prohemio III/3 (Madrid, Diciembre 1972), 409452.

- (1972). «Sobre las posibilidades de construir una poética estructural». En Comunicación, ed. (1972), 161-166. «Die Strukturale Poetik ist Eine Generative Poetik», Literaturwissenschaft und Linguistik 3 (Frankfurt, 1972), 239-264. «Structural Poetics Is a Generative Poetics», en Lucid, ed. (1977), 175-192.

\section{BIBLIOGRAFÍA SOBRE LOTMAN Y LA ESCUELA SEMIÓTICA DE TARTU-MOSCÚ.}

ABAD, F. (1985). «Crítica contemporánea: Formalismos». En J. M. Díez Borque (ed.), Métodos de estudio de la obra literaria, 588-590. Madrid: Taurus.

AlbalAdeJo MAYORDOMO, T. (1984). «La crítica lingüística». En P. Aullón de Haro (coord.), Introducción a la crítica literaria actual, 141-207. Madrid: Playor. 
ARQUÉS, R. (1993). «Iuri Lotman, la mort ignorada d'un semiòleg ignorat en vida», Avui, Barcelona (12 de diciembre de 1993), 29.

BAJTín, M. M. (1979). Estética de la creación verbal. México: Siglo XXI, 1982, 339-348.

BARAN, H. (1974). «Introduction». En Baran, ed. (1974), vii-xx.

BAYLEY, J. (1972). «Some Recent Developments in the Study of Russian Versification». Language and Style 3 (1972), 155-191.

BAyley, R. W. (1976). «Maxwell's Demon and the Muse». Dispositio 1, 3 293-302.

BERDNIKOV, G. (1981). «La poética histórica en la URSS». Criterios 5/12 (La Habana, 1983-1984), 304-310.

BONAFIN, M. (1984). «Tipologia della cultura e carnavale. Nota sui modelli di Bachtin e Lotman». L'imagine riflessa VII, 1/2 (1984).

BRoMS, H. (1987). "Autocommunication -a Way to Induce Visions to the Organization». En Broms y Kaufmann, eds. (1987), 125-138.

CÁCERES SÁNCHEZ, M. (1992). «Lenguaje, cultura, semiosfera». En Investigaciones Semióticas $V$. Semiótica y Modernidad. Actas del V Congreso Internacional de la Asociación Española de Semiótica (Celebrado en La Coruña, 3-5 de diciembre de 1992), Volumen I, 129-136. A Coruña: Universidade da Coruña/Asociación Española de Semiótica, 1994.

- (1993). «Presentación. La Escuela Semiótica de Tartu-Moscú, treinta años después». Discurso. Revista Internacional de Semiótica y Teoría Literaria 8, 7-20.

Calabrese, O. (1985). El lenguaje del arte. Barcelona: Paidós, 1987, 186-192.

CHAMPAGNE, R. A. (1978). «A Grammar of the Languages of Culture: Literary Theory and Yury Lotman's Semiotics». New Literary History 9, 2, 205-210.

CAPRetTini, G. P. (1994). «Jurij Lotman la semiotica di confine». Lexia 2 (febbraio), 1.

ChERnov, I. (1987). «Historical Survey of Tartu-Moscow Semiotic School». En Broms y Kaufmann, eds. (1987), 7-16.

- (1990). «Cultural Semiotics (On History and Notions of the Tartu School)», Nordic Association of Semiotic Studies, Denmark, November 1990 (en prensa).

Chistov, V. (1977). «Aktuelle Probleme der Sowjetischen Folkloristik». Jahrbuch für Volkskunde und Kulturgeschichte 20, 5, 67-83.

CORTI, M. (1973). «L'arte come modo di "informazione"», Il Giorno, 17 enero. [A propósito de la primera edición italiana de La estructura del texto artístico].

- (1994). «Introduzione» a Lotman, Cercare la strada, 7-13.

DANow, D. K. (1986). «Dialogic Perspectives: The East European View (Bakhtin, Mukarovsky, Lotman)». Russian, Croatian and Serbian, Czech and Slovac, Polish Literature 20 (August), 119-192.

- (1987a). «Bakhtin and Lotman: Novel and Culture». En Broms y Kaufmann, eds. (1987), 233-244.

- (1987b). «Lotman and Uspensky: a Perfusion of Models». Semiotica 64, 3/4, 343-357.

DOMÍNGUEZ CAPARRós, J. (1978). «La teoría literaria rusa postformalista». En Crítica Literaria, Madrid, Universidad Nacional de Educación a Distancia, $1989^{2}, 377-383$.

EAGLE, H. (1976). «The Semiotics of the Cinema: Lotman and Metz». Dispositio $1,3,303-314$. 
- (1981). «Verse as Semiotic System: Tynjanov, Jakobson, Mukarovsky, Lotman Extended». Slavic and East European Journal 25, 4, 47-61.

EAGLETON, T. (1983). Una introducción a la teoría literaria. México: Fondo de Cultura Económica, 1988, 125-128.

Eco, U. (1969). «Lezione e contradizione nella semiotica sovietica». En Faccani y Eco, eds. (1969), 13-31.

- (1988). «Lotman y la "glasnost"». El País, Madrid, (6 de febrero), 10.

- (1990). «Introduction» a Lotman. Universe of the Mind, vii-xiii.

EIMERMACHER, K. (1977). «Some Aspects of Semiotic Studies of the Moscow and Tartu Schools». En Eimermacher y Shishkoff (1977), VII-X.

FACCANI, R. (1969). «Gli autori di questo libro». En Faccani y Eco, eds. (1969), 7-11.

- (1975). «Appunti in margine ad alcuni saggi di Ju. M. Lotman». En Lotman y Uspenskij (1975), 5-24.

FleisCHer, M. (1989). Die Sowjetische Semiotik. Theoretische Grundlagen der Moskauer und Tartuer Schule. Tübingen: Stauffenburg.

FoKKeMA, D. W. (1976). «Continuity and Change in Russian Formalism, Czech Structuralism, and Soviet Semiotics». PTL. A Journal for Descriptive Poetics and Theory of Literature 1, 153-196.

FoKKeMA, D. W. e IBSCH, E. (1981). Teorías de la literatura del siglo $X X$. Madrid: Cátedra, 56-68.

GARCIA BERRIO, A. (1973). Significado actual del formalismo ruso. Barcelona: Planeta, 394-404.

Gasparov, B. M. (1985). "Introduction”. En Nakhimovski, A. D. y Stone, A., eds. (1985), 13-29.

GodzICH, W. (1978). «The Construction of Meaning». New Literary History 9, 2, 389-397.

GoNZÁleZ, C. (1982). Función de la teoría en los estudios literarios. México: UNAM, 33-39 y 133-136.

GRZYBEK, P. (1989). Studien zum Zeichenbegriff der Sowjetischen Semiotik (Moskauer und Tartuer Schule). Bochum: Universitätsverlag Dr. Norbert Brockmeyer, 393 páginas.

HAMMARBERG, G. (1984). «A Reinterpretation of Tynjanov and Jakobson on Prose (with Some Thoughts on the Baxtin and Lotman Connection)». En B. Stolz, I. Titunik y L. Dolezel (eds.), Language and Literary Theory, 379404. Ann Arbor: University of Michigan.

HoPPAL, M. (1987). «Ethnosemiotics and Semiotics of Culture». En Broms y Kaufmann, eds. (1987), 17-33.

HYMES, D. (1978). «Comments on Soviet Semiotic and Criticism». New Literary History $9,2,399-411$.

JonAID-SHARIF, L. (1984). «Text-Sign-Structure: The Poetics of Jurij Lotman». Dissertation Abstracts International 45, 4 (Oct.).

KozhINOV, V. V. (1973). «50 años de poética en la URSS». La Gaceta de Cuba. Criterios [Primera época], 107 (La Habana).

KRISTEVA, J. (1968). «Linguistique et sémiologie aujourd'hui en URSS». Tel Quel 35, 3-8.

- (1969a). «La sémiologie comme science des idéologies». Semiotica 1, 196204.

- (1969b). «L'expansion de la sémiotique». En Semeiotiké. Recherches pour une sémanalyse. París: Seuil, 43-59; y en Kristeva y otros, eds. (1971). 
KUPER, C. (1979). «Roman Jakobson und Jurij Lotman: Die Entwicklung einer semiotischen Asthetik». En Arbeiten zur Sprachentwicklung und Sprachbescheibung, 30-62. Berlin: Institut für Linguistik, Technische Universität Berlin.

LachmanN, R. (1982). «Wertaspekte in Jurij Lotmans Textbedentungstheorie». En B. Lenz y B. Schulte-Middelich (eds.), Beschreiben, Interpretieren, Werten: Das Wertungsproblem in der Literatur aus der Sicht unterschiedlicher Methoden, 134-155. Munich: Fink.

LACHMANN, R., Eshelman, R. y DaVIS, M. (1987). «Value Aspects in Jurij Lotman's Semiotics of Culture/Semiotics of Text». Dispositio, 12, 30-32, 13-33.

LAFERRIERE, D. (1978). «Semiotica sub specie Sovietica: Anti-Freudianism, Pro-Marxism and Other Disturbing Matters». PTL. A Journal for Descriptive Poetics and Theory of Literature, 3.

LHOEST, F. (1979). «Regards sur la sémiotique soviétique». En André Helbo (ed.), Le champ sémiologique, R1-22. Bruselas, Complexe.

LOZANO, J. (1979). «Introducción a Lotman y la Escuela de Tartu». En Lotman y E. de Tartu (1979), 9-37.

LUCID, D. P. (1977). «Introduction». En Lucid, ed. (1977), 1-23.

MARCHÁN FIZ, S. (1970). "[Reseña de I sistemi di segni e lo strutturalismo sovietico]». Revista de Ideas Estéticas 110 (1970), 140-142.

MARCIALIS, N. (1993). «Introduzione all'edizione italiana. Boris Andreevič Uspenskij e il dibattito sulla storia della lingua letteraria russa». En B.A. Uspenskij, Storia della lingua letteraria russa, 11-34.

MARGOLIN, U. (1975). «Juri Lotman on the Creation of Meaning in Literature». Canadian Review of Comparative Literature (Fall, 1975), 262-282.

MARKIEWICZ, H. (1981). «Die Literatur aus semiotischer Sicht: Randbemerkungen zu den Arbeiten J. Lotmans». En P. Zima (ed.), Semiotics and Dialectics. Ideology and the Text, 331-359. Amsterdam: Benjamins.

MATEJKA, L. (1976). «Languages of Art in Soviet Semiotics». Dispositio 1, 3, 207-212.

MAYENOWA, M. (1977). «Lotman as an Historian of Literature». Russian Literature, 5, 1, 81-90.

MEIJER, J. M. (1973). «Literature as Information. Some Notes on Lotman's Book: Structura xudozestvennogo teksta». En Eng y Grygar, eds. (1973), 209-223.

- (1977). «A Reply to Ju. Lotman». Russian Literature 5, 1, 61-80.

MeletinskiJ, E. M. y SegAL, D. M. (1971). «Estructuralismo y semiótica en la URSS». La Gaceta de Cuba. Criterios [Primera época], 100 (La Habana, 1972). «Structuralism and Semiotics in the USSR», Diogenes, 73 (1971), 88125.

MICELI, S. (1982). In nome del segno: Introduzione alla semiotica della cultura. Palermo: Sellerio.

MYASNIKOV, G. (1973). «Yury Mikhailovich Lotman: An Essay-Tribute on the Fiftieth Anniversary of his Birth». Russian Literature 6, 575-578.

NAVARRO, D. (1986). «Textos y contextos: un balance, un inicio». En Textos y contextos: Una ojeada en la teoría literaria mundial (Selección, traducción y prólogo de Desiderio Navarro), Vol. I, 7-19. La Habana: Arte y Literatura.

- (1993). «Mostrar la Escuela de Tartu como escuela: más allá de Lotman y Uspenski». Escritos. Revista del Centro de Ciencias del Lenguaje 9 (Puebla, México), 7-13. 
- (1994). «A la memoria de Iuri Lotman (1922-1993), sabio, colaborador, amigo». Criterios 31 (La Habana), 203-205.

OGuibenine, B. (1979). «Linguistic Models of Culture in Russian Semiotics:

A Retrospective View». PTL. A Journal for Descriptive Poetics and Theory of Literature 4, 91-118.

- (1981). «The Semiotic Approach to Human Culture». En W. Steiner (ed.). Image and Code. Ann Arbor: Michigan Studies in Humanities.

- (1987). «On the World Tree Symbolism: the Sources of an Analytical Pattern». En Broms y Kaufmann, eds. (1987), 35-50.

Pesonen, P. (1994). «St. Petersburg as a Myth and a Text in Russian Culture and Literature». Genius loci. Symposium of the Finnish Society of Semiotics, Imatra, July (mecanografiado).

Peters, J.-U. (1981). «Textdeskription und Textdentung: Zu Jurij Lotmans Analysen russischer Lyrik des 19. und 20. Jahrjunderts». Russian Literature $10,1,91-110$.

POSNER, R. (1987a). «Semiotics vs. Anthropology: Alternatives in the Explication of "Culture"». En Broms y Kaufmann, eds. (1987), 151-184.

- (1987b). «Zur Entwicklung der Semiotik». En Broms y Kaufmann, eds. (1987), 185-190.

- (1991). «Semiótica de la cultura y teoría de los textos». Revista de Estética 8 (Buenos Aires).

Pozuelo, J. M. ${ }^{a}$ (1988). Teoría del lenguaje literario. Madrid: Cátedra, 69-74.

- (1994). «Realidade, ficción e cultura». Grial 123, Tomo XXXII (XulloSetembro), 295-308.

RADAR, E. (1974). «Pour une science de la littérature: La structure du texte artistique de Jouri Lotman». Le Langage et l'Homme 24 (Janvier), 64-68.

REID, A. (1990a). «Who is Lotman and Why is Bakhtin Saying Those Nasty Things about Him?», Discours Social/Social Discourse 3, 1-2, 325-338.

- (1990b). Litterature as Communication and Cognition in Baxtin and Lotman. University of Alberta.

- (1991). «The Moscow-Tartu School on Bakhtin». S. European Journal for Semiotic Studies [Dialectics, Semiotics, Materialism. In Memoriam F. Rossi-Landi (eds. J. Bernard, J. Kelemen, G. Withalm)], 3, 1/2.

REvzinA, O. G. (1972). «The Fourth Summer School on Secondary Modeling Systems Tartu 17-24 August 1970». Semiotica 6, 222-243.

REWAR, W. (1976a). «Tartu Semiotics». Bulletin of Literary Semiotics 3, 1-16.

- (1976b). «Semiotics and Communication in Soviet Criticism». Language and Style 9 (1976), 3-16.

ROSNER, K. (1984). «On Some Difficulties Involved in Lotman's Concept of the Semiotics of Culture». En J. Pelc et al. (eds.), Sign, System and Function. Berlin: Mouton.

RUDY, S. (1986). «Semiotics in the USSR». En T. A. Sebeok y J. UmikerSebeok, eds., The Semiotic Sphere, 555-582. New York: Plenum Press.

SALVESTRONI, S. (1981). «Postfazione» [a Lotman T, 1981]. Strumenti Critici XV, I (Torino, Febbraio), 30-45.

- (1982). «I meccanismi dialogici e la crescita della conoscenza nella teoria semiotica di Lotman». Intersezioni 1.

- (1985). «Nuove chiavi di lettura del reale alla luce del pensiero di Lotman e dell'epistemologia contemporanea». En Lotman, La semiosfera, 1985, 7-46.

SALVo, M. DI (1988). «Presentazione» a B.A. Uspenskij. Storia e Semiotica, 1980 , VII-XV. 
SCHNAIDERMAN, B. (1979). «Semiótica na U.R.S.S. -Uma busca dos "elos perdidos" (À guisa de Introdução)». En B. Schnaiderman, ed. (1979), 9-27.

SEBEOK, T. A. (1987). "In What sense is language a "primary modeling system"?». En Broms y Kaufmann, eds. (1987), 67-80; y en T. A. Sebeok, $A$ Sign Is Just A Sign, Bloomington: Indiana University Press, 1991.

SEGAL, D. M. (1973). «Las investigaciones soviéticas en el campo de la semiótica en los últimos años». En Lotman y E. de Tartu (1979), 225-245. «Le ricerche sovietiche nel campo della semiotica negli ultimi anni», en Lotman y Uspenskij, eds. (1973).

- (1974). Aspects of Structuralism in Soviet Philology. Tel-Aviv: Tel-Aviv University (Papers on Poetics and Semiotics, 2), 135 páginas.

Segre, C. (1977). Semiótica, Historia y Cultura. Barcelona: Ariel, 1981, 7-45.

- (1984). «Culture et texte dans la pensée de Yury M. Lotman». En M. Halle et alii, eds. (1984), 3-15.

- (1985). Principios de análisis del texto literario. Barcelona: Crítica, 143-172.

SHISHKOFF, S. (1977). «Note». En Eimermacher y Shishkoff (1977), XI-XII.

SHukMAN, A. (1976). "The Canonization of the Real. Jurij Lotman's Theory of Literature and Analysis of Poetry». PTL. A Journal for Descriptive Poetics and Theory of Literature, 1, 317-338.

-.- (1977a). «Jurij Lotman and the Semiotics of Culture». Russian Literature 5, 1, 41-54.

- (1977b). Literature and Semiotics. A study of the writings of Yu. M. Lotman. Amsterdam: North Holland Publishing Company.

- (1978). «Soviet Semiotics and Literary Criticism». New Literary History 9, 2, 189-197.

- (1981). «The Dialectics of Change: Culture, Codes and the Individual». En P. Zima (ed.), Semiotics and Dialectics. Ideology and the Text, 311329. Amsterdam: Benjamins.

- (1982). The New Soviet Semiotics. London.

- (1986). «Culture: The Moscow-Tartu School». En T. A. Sebeok (ed.), Encyclopedic Dictionary of Semiotics. Berlin/New York/Amsterdam: Mouton de Gruyter.

- (1987). «Towards a Poetics of the Absurd: The Prose Writings of Daniil Kharms». En Broms y Kaufmann, eds. (1987), 81-95.

- (1989). «Semiotics of Culture and the Influence of M. M. Bakhtin». En Eimermacher et alii, eds. (1989), 193-207.

Silvio AVAlLE, D'A. (1980). «La cultura nella tradizione russa del XIX e XX secolo». Strumenti Critici $42 / 43$ (Torino, Ottobre), 195-211; y, con modificaciones, «Il problema della cultura nella filologia e linguistica russe del XIX e XX secolo», en D'Arco Silvio Avalle (a cura di), La cultura nella tradizione russa del XIX e XX secolo, Torino: Einaudi («Paperbacks»), 1982, 5-66.

SMIRNOV, I. P. (1987). «Totemismus und Genretheorie». En Broms y Kaufmann, eds. (1987), 97-111.

SteIner, P. (1976). «On Semantic Poetics». Dispositio 1, 3, 339-348.

STEINER, W. (1976). «Point of View from the Russian Point of View». Dispositio, 1, 3, 315-327.

STRADA, C. (1984). «Introduzione» a Lotman. Da Rousseau a Tolstoj, 9-39.

STRADA, V. (1964). «Formalismo e neoformalismo». Questo e altro, 6/7, 51-56.

- (1985). «Introduzione all'edizione italiana: Poesia e realtà nello Evgenij Onegin». En Lotman, Il testo e la storia, 1985, 5-44.

TALENS, J. (1978a). «Práctica artística y producción significante. Notas para 
una discusión». En J. Talens y otros, Elementos para una semiótica del texto artístico, 15-60. Madrid: Cátedra, 19884.

(1978b) «Teoría y técnica del análisis poético». En J. Talens y otros, Elementos para una semiótica del texto artístico, 63-109. Madrid: Cátedra, 19884.

TALVET, J. (1993). "Tartu como signo». Discurso. Revista Internacional de Semiótica y Teoría Literaria 8, 21-28.

TITUNIK, I. (1976). «M. M. Baxtin (The Baxtin School) and Soviet Semiotics». Dispositio 1, 3, 327-338.

TODOROV, T. (1972). «La poétique en URSS». Poétique 9, 102-115.

Tolvonen, P.-M. (1987). «Yu. M. Lotman's Concept of Poetic Language and Poetic Text: The Example of Baudelaire's Spleen II». En Broms y Kaufmann, eds. (1987), 191-197.

TOROP, P. (1982). «El fenómeno Lotman». Criterios 5/12 (La Habana), 90-98. - (1992). «La Escuela de Tartu como Escuela». Discurso. Revista Internacional de Semiótica y Teoría Literaria 8 (1993), 31-45.

TOUMANOFF, S. (1990). "Afterword to Yury Lotman's “Artistic Space in Gogol's Prose"», Russian Literature 24, 243-251.

USPENSKI, B. A. (T, 1987). «Sobre el problema de la génesis de la Escuela Semiótica de Tartu-Moscú». Escritos. Revista del Centro de Ciencias del Lenguaje 9 (Puebla, México, 1993), 199-212.

VÁzQUEz MEDEL, M. Á. (1993). «In Memoriam Iuri M. Lotman». Discurso. Revista Internacional de Semiótica y Teoría Literaria 8, 3-5.

VENCLOVA, T. (1967). «Le colloque sémiotique de Tartu». Information sur les sciences sociales 4, 123-129; y en Kristeva y otros, eds. (1971), 574-580.

VETIK, R. (1994). «The Platonism of J. Lotman». Semiotica 99, 1/2, 67-79.

VolGT, V. (1987). «Between Eastern and Western Semiotics». En Broms y Kaufmann, eds. (1987), 51-56.

VROON, R. y VROON, G. (1976). «V. V. Ivanov's Essays on the History of Semiotics in the USSR». Dispositio 1, 3.

WAHNÓN, S. (1991). Introducción a la historia de las teorías literarias. Granada: Universidad, 106-109.

WINNER, I. P. (1979). «Ethnicity, Modernity, and Theory of Culture Texts». Semiotica 27, 1/3, 103-147.

- (1984a). «Some Comments Upon Lotman's Concepts of Semiotics of Culture: Implications for the Study of Ethnic Culture Texts». En Halle et alii, eds. (1984), 28-36.

- (1984b). «Theories of Narration and Ethnic Culture Texts». En J. Pelc, Sebeok, Stankiewicz y T. Winner, eds., Sign, System and Function.

Papers of the First and Second Polish-American Semiotics Colloquia, 439-455. Berlin: Mouton de Gruyter.

- (1988). «Research in Semiotics of Culture». En T. A. Sebeok y J. Umiker-Sebeok, eds., The Semiotic Web 1987, 601-619. Berlin-New YorkAmsterdam: Mouton de Gruyter.

- (1989). «Segmentation and Reconstruction of Ethnic Culture Texts. Narration, Montage, and the Interpenetration of the Visual and Verbal Spheres». En Eimermacher, Grzybeck y Witte, eds. (1989), 411-431.

WINNER, I. P. y WINNER, T. (1976). «The Semiotics of Cultural Texts». Semiotica 18, 2, 101-156.

WINNER, T. (1968). «Introduction», a Y. Lotman, Lektsii po strukturalnoi poetike. Rhode Island: Brown University Press.

YAMAGUCHI, M. (1987). "Center" and "Periphery" in Japanese Culture -in Light of Tartu Semiotics». En Broms y Kaufmann, eds. (1987), 199-219. 